\title{
Does Inconvenience Explain Low Take-Up? Evidence from Unemployment Insurance
}

\section{Avraham Ebenstein Kevin Stange}

\begin{abstract}
Application inconvenience is one popular explanation for why many individuals do not receive the social benefits for which they are eligible. Applications take time and some individuals may decide that the financial benefits do not outweigh these time costs. This paper investigates this explanation using cross-state variation in administrative changes that made applying for unemployment insurance (UI) benefits substantially more convenient over the past decade. We find that the introduction of phone- and Internet-based claiming did not have an appreciable impact on overall UI take-up, nor did it lead to a shift toward recipients that are higher income or likely to be receiving the maximum benefit amount. These findings are inconsistent with a time- and transaction-cost explanation for low take-up, since remote UI claiming is less time intensive. This suggests that reducing application barriers alone may not be an effective tool for increasing program participation. (C) 2010 by the Association for Public Policy Analysis and Management.
\end{abstract}

\section{INTRODUCTION}

Participation varies considerably across most social programs in the United States and is generally less than complete. In her extensive survey of the empirical evidence, Currie (2006) finds that take-up rates for means-tested programs range from very low (8 to 14 percent for State Children's Health Insurance Program) to relatively high (82 to 87 percent for the Earned Income Tax Credit and 60 to 90 percent for Temporary Assistance for Needy Families), with most other major social programs falling somewhere in between. Take-up of non-means-tested programs is generally higher (nearly 100 percent for Medicare), but often far from complete (72 to 83 percent for unemployment insurance). The latter is particularly puzzling if one expects the stigma associated with participation in non-means-tested programs to be lower than that associated with means-tested ones. She concludes that concrete transaction costs-including inconvenience-must also be a major determinant of participation in social programs among those eligible.

Most research on take-up has focused on monetary incentives. ${ }^{1}$ However, there is a small but growing body of recent work suggesting that non-monetary program

\footnotetext{
${ }^{1}$ For example, McCall (1995) and Anderson and Meyer (1997) find strong effects of benefit levels on takeup of unemployment insurance. Daponte, Sanders, and Taylor (1999) find that poor information partially explains food stamps nonparticipation, and poor information is most common among those whose potential benefits are low.
} 
features such as application complexity, default or automatic enrollment, or mandated in-person interviews may also be important factors in participation. ${ }^{2}$ In this paper, we examine the take-up consequences of the recent introduction of phoneand Internet-based claiming for unemployment insurance (UI), which greatly reduced the time required to file for UI benefits. ${ }^{3}$ While almost all unemployed workers were historically required to initially apply for UI benefits in person, now only 13 percent do. We exploit cross-state variation in the timing of these changes to identify the effect of inconvenience on the number and characteristics of UI recipients. The present study is most closely related to that of Kopczuk and Pop-Eleches (2007), who find that the introduction of electronic state tax filing had a large effect on participation in the EITC.

We find that the aggregate unemployment insurance take-up rate has increased slightly over the past decade and a half, in contrast to the declining take-up observed in the $1980 \mathrm{~s} .{ }^{4}$ This trend coincides with dramatic changes in the ease of applying for benefits and, more recently, increases in benefit levels and a shift toward more educated unemployed workers. However, state-level estimates suggest that increased ease of filing is not behind this aggregate take-up trend. The fraction of unemployed who are on UI has no relationship to the introduction of phone- or Internet-based claiming or to the closing of UI offices. This result is robust to controls for state and year effects, characteristics of the unemployed, and the maximum benefit amount. Regressions using estimated take-up as a dependent variable are generally consistent with this finding, but are much less precise due to measurement error in our estimates of the fraction of unemployed who are eligible for UI.

We also find little evidence of a shift toward higher-wage claimants resulting from reduced UI application time, as a time-cost explanation for low take-up would predict. The introduction of phone claiming had no effect on the fraction of claimants receiving the maximum benefit, the average and distribution of pre-unemployment wage, or claimant education. The only exception to this pattern for Internet claiming is an increase in the proportion receiving the maximum benefit when Internet claiming is introduced. The primary effect of the introduction of remote claiming technology was to reduce states' payroll costs, but with no effect on the number or pool of UI participants. This finding leaves incomplete UI take-up an unresolved puzzle. Incomplete information about eligibility and application processes, rather than application inconvenience, are possible unexplored explanations that should be examined in future work.

This paper is organized as follows. The next section presents recent trends in UI participation and provides background on UI claiming procedures in the U.S. Section 3 describes our data and empirical approach. Results are reported in Section 4. Section 5 concludes.

\footnotetext{
2 In their survey, Remler, Rachlin, and Glied (2001) highlight the importance of non-monetary program features to take-up. Currie and Grogger (2002) find that Medicaid administrative reforms did not increase use of prenatal services, but non-monetary design features do seem to be important to SCHIP participation (Bansak \& Raphael, 2006; Wolfe \& Scrivner, 2005). Ketsche et al. (2007) find that stigma is one channel through which the effect of non-monetary program features may operate. Currie and Grogger (2001) and Hanratty (2005) find that longer recertification intervals and reductions in state certification requirements increase food stamp participation. In the area of retirement savings, see Madrian and Shea (2001) on the importance of automatic/default enrollment and Saez (2009) on the importance of program framing.

${ }^{3}$ Needels et al. (2000) report results from claimant surveys that suggest considerable time savings. Marcus and Frees (1998) report results from a nationwide survey of 2,773 claimants, in which respondents estimated that it took 11 minutes to file an initial claim by telephone and 61 minutes to file in person.

${ }^{4}$ See Blank and Card (1991) for UI take-up trends in this earlier period.
} 
Does Inconvenience Explain Low Take-Up? / 113

\section{BACKGROUND}

\section{Aggregate Trends in Unemployment Insurance}

The federal-state UI program provides income support during spells of unemployment to workers in almost all sectors of the economy. Most of the research on UI participation is motivated by three features: (1) low levels of participation among those eligible; (2) large cross-state differences in participation; and (3) long-term declines in participation, particularly in the early 1980s. Two supplements to the Current Population Survey (CPS) in 1989 to 1990 and 1993 asked unemployed workers whether they had applied for UI benefits and, if not, why not. As summarized in Wandner and Stettner (2000), the most common reason for non-application was perceived ineligibility (mostly due to insufficient work hours, earnings, and quits) and optimistic job expectations. ${ }^{5}$ Responses suggestive of lack of information ("Didn't know about UI or how to apply"), inconvenience ("Too much work or hassle"), or stigma ("Too much like charity or welfare") were relatively rare. ${ }^{6}$

There is also considerable variation in UI participation across states and regions. Vroman (2002) investigates the sources of this variation and concludes that low participation is linked to high rates of misconduct determination and frequent eligibility determination by states. Unionization and the prevalence of employer-initiated claims also tend to increase UI participation (Budd \& McCall, 1997, 2004).

There has also been a fair amount of attention paid to the decline in aggregate UI participation over the past half-century, particularly in the early 1980s. Blank and Card (1991) conclude that none of this recent decline is due to changes in eligibility. Instead, changes in the regional distribution of unemployment from high to low take-up states and declines in unionization explain most of the recent decline in participation. Anderson and Meyer (1997) conclude that changes in the tax treatment of UI benefits account for most of the decline not explained by Blank and Card (1991).

In contrast to declines observed in the 1980s, we estimated that the aggregate UI take-up rate has increased slightly over the past decade and a half. Figure 1 plots our estimates of the fraction of unemployed workers that are eligible for UI, the fraction that are receiving UI benefits, and the implied take-up rate from 1989 to 2006 (the construction of these measures is described in a later section). Fraction eligible and fraction on UI generally trend together-increasing during recessions and falling during recovery. The gap between these series narrowed during the 1990s, particularly during the 2001 recession, increasing the take-up rate.

Coincident with this take-up increase, states made it much less burdensome to apply for UI benefits. Figure 2 plots the fraction of all initial UI claims that were filed using various methods from 1989 to 2006. Though nearly all initial claims for benefits were made in person in 1990, by 2006 only 13 percent were. More than half of all initial claims are now made over the phone and more than 30 percent are filed online. While suggestive of a relationship between claiming ease and participation, this interpretation is obscured by changes in program generosity and the characteristics of unemployed workers during this period. Figure 3 plots the average maximum weekly benefit amount UI recipients are eligible for and the fraction of unemployed workers that have a bachelor's degree over time. UI generosity grew gradually during the 1990s and jumped considerably after 2000. The composition

\footnotetext{
${ }^{5}$ Unfortunately, actual eligibility determination was not possible because survey respondents were not matched to administrative data. It was therefore not possible to assess whether self-reported perceived ineligibility was accurate.

${ }^{6}$ These findings are similar to tabulations we have conducted for the May 2005 CPS supplement among non-filers for UI. Of 3,511 non-filers included in the supplement, 1,899 reported "did not think eligible" as a reason for their decision to not file. In contrast, only 85 survey participants reported "too much work" and only 35 reported "too much like charity" as a reason.
} 


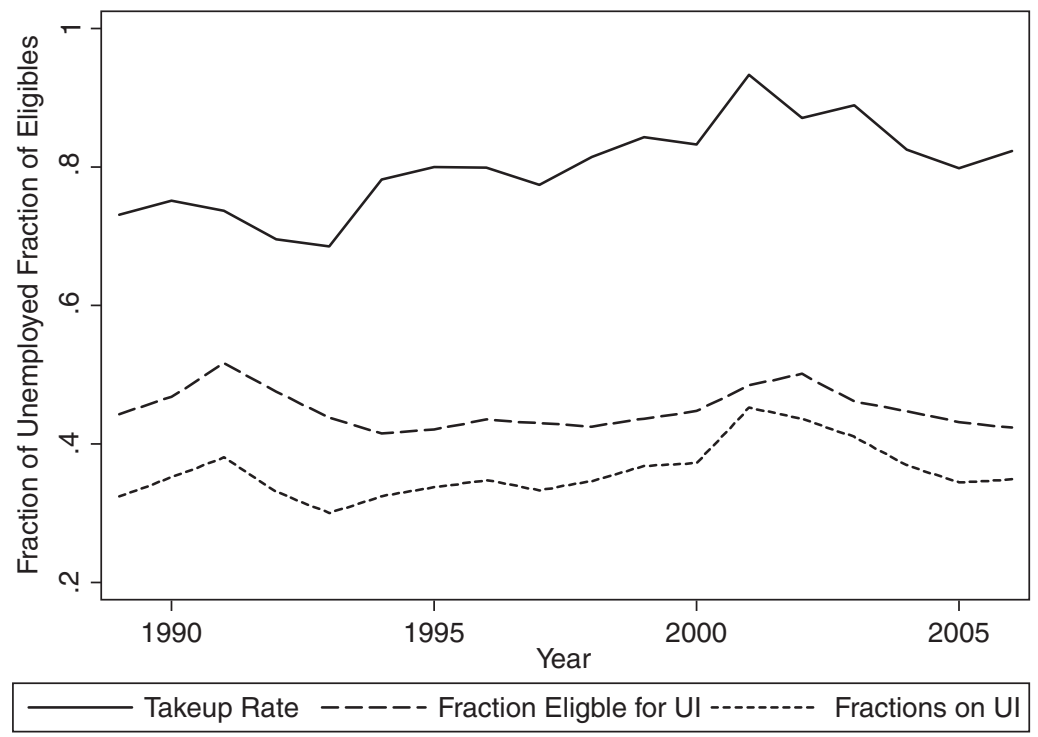

Sources: Fraction of unemployed on UI is from DOL administrative records, and fraction of unemployed eligible for UI is estimated by the authors using the March CPS. See text for details on eligibility imputation. Take-up is the ratio between these two variables. These measures were constructed at the state-year level and aggregated to the U.S. using the number of unemployed workers as weights.

Figure 1. Aggregate Participation in Unemployment Insurance.

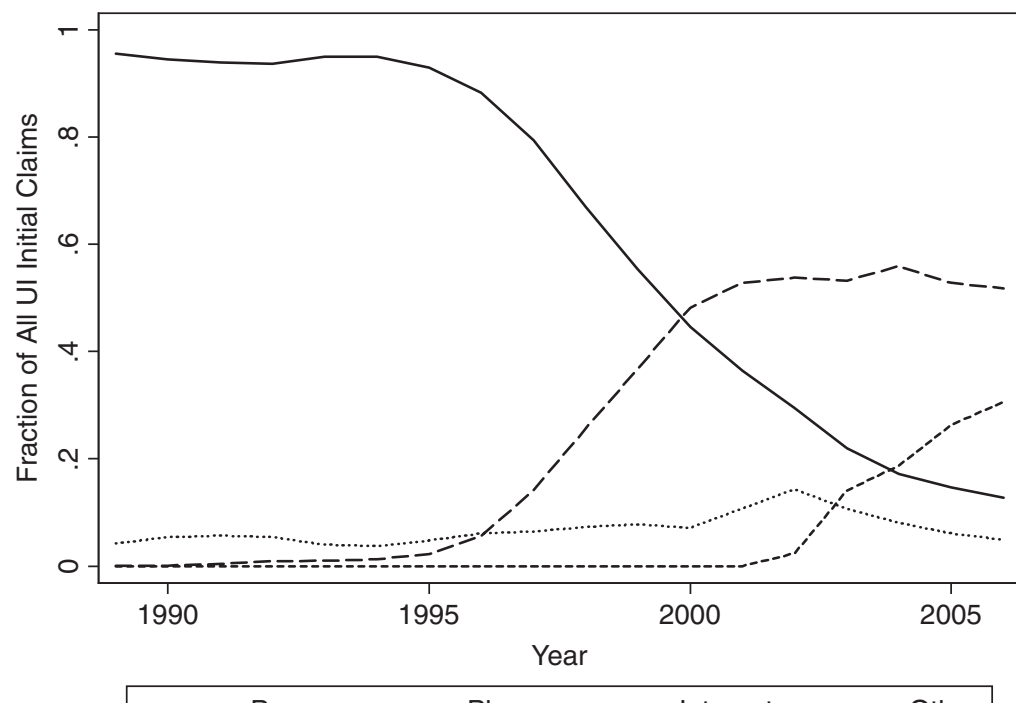

Person -----Phone

Internet

Other

Sources: Authors' calculations using BAM data. See text for details. Fractions were constructed at the state-year level and aggregated to the U.S. using number of UI claimants as weights.

Figure 2. Unemployment Insurance Claiming Method. 


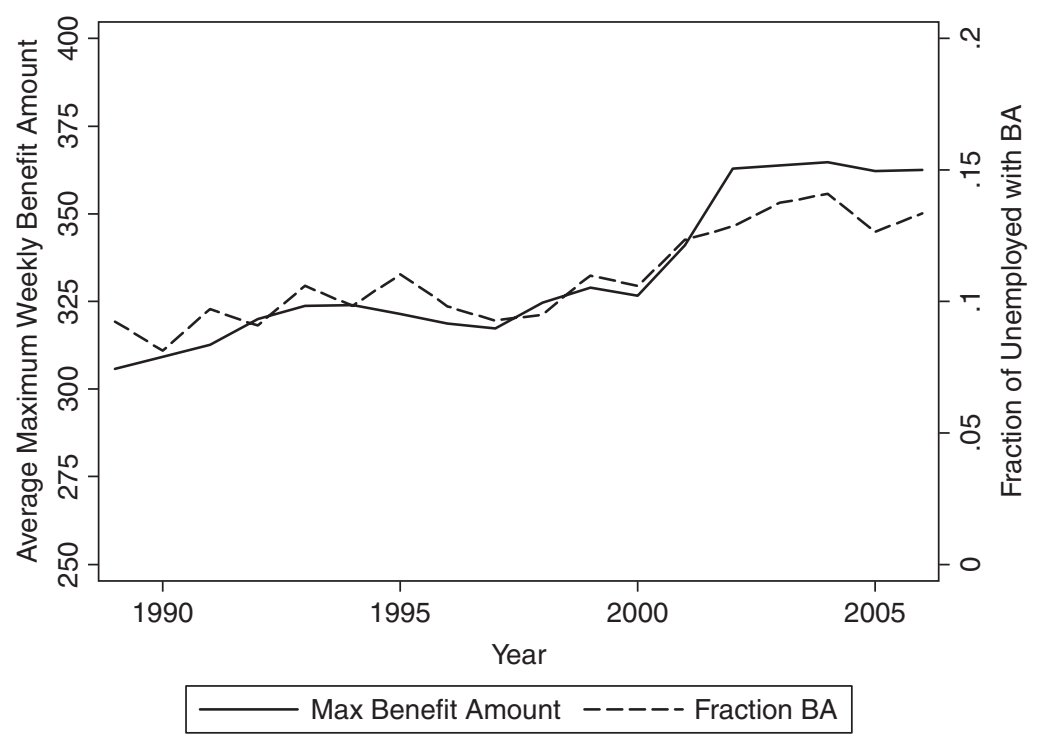

Sources: Maximum benefit amount $(\$ 2003)$ is from the DOL ETA Significant Provisions of State Unemployment Insurance Laws. Fraction of unemployed with a BA is from authors' calculations from the March CPS. Both were estimated at the state-year level and aggregated to the U.S. using the number of unemployed workers as weights.

Figure 3. Changes in UI Generosity and Characteristics of the Unemployed.

of unemployed workers also shifted, with the 2001 recession bringing more educated workers into the ranks of the unemployed. These aggregate changes in program generosity and the characteristics of the unemployed (and potential UI eligible), both of which may affect UI participation, motivate the cross-state analysis that follows.

\section{Changes to UI Claiming Procedures}

Since the program's inception in 1935, most workers who lost their jobs visited state-run local UI offices to file their initial claim, certify that they were available for work, and confirm that they were actively seeking employment. ${ }^{7}$ In the mid1990s, however, states began to implement procedures for recipients to receive initial UI claims over the telephone, and many began to close UI offices. The receipt of claims over the Internet soon followed. Figure 2 masks considerable cross-state variation in timing of these policy changes which are important for our empirical approach. We use cross-state variation in the timing of these policy changes to identify the effect of inconvenience on take-up rates. Figure 4 plots the cumulative number of states by year that have introduced telephone and Internet claiming or have closed UI offices. Colorado was the only state to offer phone initial claiming for the first half of the 1990s, followed by Wisconsin in 1995 and Massachusetts and California in 1996. Phone claiming quickly took off, and by 2005, 40 states accepted UI claims via phone. Phone claiming was usually followed-often with a 1- to 2-year

\footnotetext{
${ }^{7}$ Due to the remote nature of many of its communities, Alaska has long permitted individuals to file UI benefits through postal mail.
} 


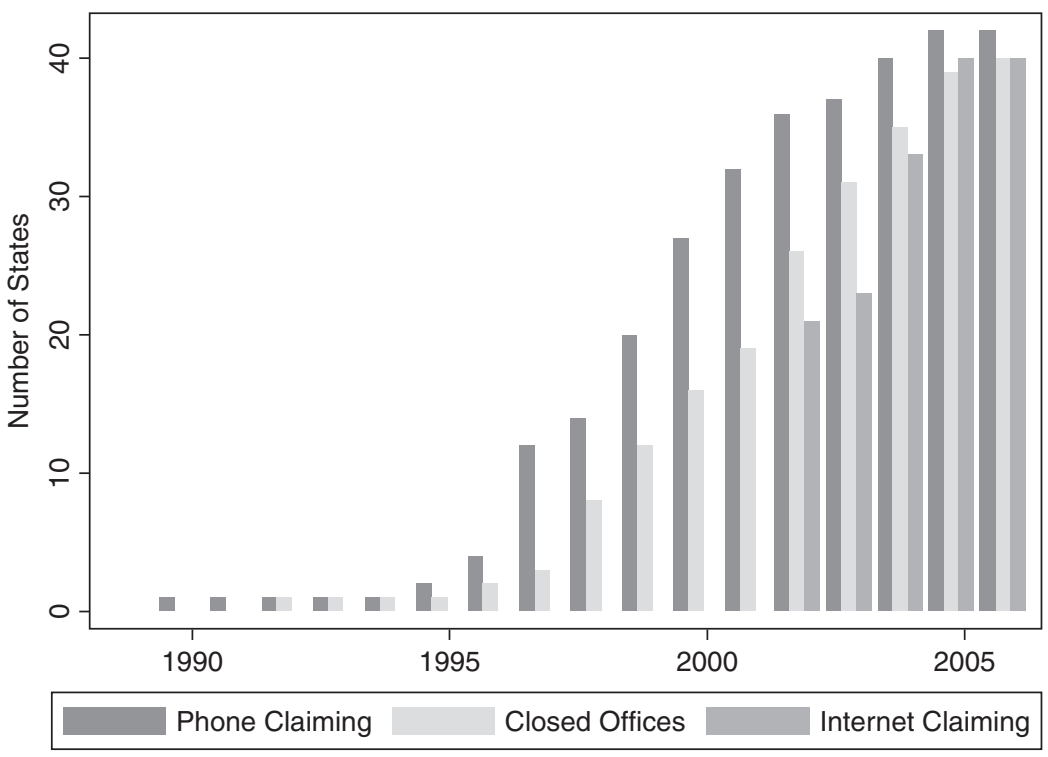

Sources: Constructed by authors from various sources. See Data and Empirical Approach section of text for details.

Figure 4. Cumulative Number of States with Policy Change.

lag-by the elimination of initial claims takers at UI offices. Internet claiming, introduced widely in 2000, was nearly as common as phone claiming by $2005 .^{8}$

Cost reduction and improved customer service were the primary motivations for states' implementation of telephone and Internet claiming. In their survey of seven early telephone claims adopters, Needels et al. (2000) found that state UI administrators switched from in-person filing at local UI offices to telephone claiming to reduce administrative costs and improve customer service. Kenyon et al. (2003) found that cost savings, improved efficiency, and convenience (extended hours and reduced wait time) also motivated the adoption of Internet claiming. The adoption of both forms of remote claiming technology were partially fueled by the availability of grants from the U.S. Department of Labor to implement these technologies, and almost all states took advantage of this funding source.

Since cost savings was a primary motivation, most states closed local UI offices (eliminating in-person filing) after the introduction of telephone claiming and instead provide dedicated on-site telephones or Internet access (or both) at local one-stop centers to use for claims filing. ${ }^{9}$ Most states make use of interactive voice response technologies to automate part of the initial claims process, and four of the seven profiled states offer toll-free numbers. Our interviews with many state UI offices suggest that phone claiming may have improved linguistic accessibility because most states utilized phone translation services. How these changes have affected access to job information and re-employment services is not clear, though

\footnotetext{
${ }^{8}$ The adoption of telephone and Internet technology for continuing claims, which usually preceded initial claims, may also have altered states' ability to assess whether current claimants are actively looking for work. However, Ashenfelter, Ashmore, and Deschenes (2005) find that increased monitoring of job searches has no effect on the duration of continuing claims, so less monitoring should not increase durations. Additionally, we do not expect the adoption of automatic continuing claims to alter convenience much, since many continuing claims were filed via postal mail (a convenient method) prior to the adoption of automatic continuing claims (O'Leary, 2006).
} 
interviews in a recent GAO report (U.S. Government Accountability Office, 2005) suggest it has not been diminished.

Important for the interpretation of our findings is whether phone and Internet claiming is more convenient than in-person claiming, since most states eliminated the in-person filing option following the introduction of telephone claiming. ${ }^{10}$ As reported in Needels et al. (2000), customer satisfaction surveys in Maine, Massachusetts, Missouri, and Wisconsin suggest that claimants overwhelmingly prefer telephone to in-person claiming. In these states, 86 to 96 percent of respondents, half of whom are former in-person filers, report that telephone claiming is easier, more convenient, or faster. ${ }^{11}$ The case of Massachusetts is also illustrative. Despite being given the option to file in person, only 11 percent of individuals chose to do so in 2003. Kenyon et al. (2003) report that claimants seem to be even more satisfied with Internet-based claiming due to its convenience and speed. ${ }^{12}$ Though far from conclusive, these anecdotes suggest that remote claiming methods are overwhelmingly preferred to in-person methods. ${ }^{13}$

Figures 5 and 6 examine which baseline factors predict when states implemented remote claiming. Figure 5 plots year of policy change by four different demographic characteristics from the 1990 Census. Phone claiming was implemented earlier by states with higher household income, more educated populations, and fewer minorities. Surprisingly, rural states who presumably have the greatest to gain from remote claiming were late adopters. There is much less variation in the timing of Internet adoption, but the adoption pattern is similar: Higher income, education, and urbanization all predict earlier adoption.

Figure 6 repeats this analysis for four baseline labor market and UI program characteristics. Early adoption has only weak correlation with low unemployment, but is positively correlated with UI benefit generosity. The bottom panels show the correlation between adoption and measures of UI program coverage. States in which more unemployed workers were eligible or receiving UI (or both) in 1990 were more likely to introduce phone and Internet claiming earlier. Since timing of adoption was clearly not random among the states, our difference-in-difference approach controls for fixed differences in take-up between states.

\section{DATA AND EMPIRICAL APPROACH}

We construct a panel data set of states (plus the District of Columbia) for the years 1989 to 2006 from several different sources. Information on UI claimants is from the Benefit Accuracy Measurement (BAM) program, administered by the U.S. Department of Labor. BAM is designed to measure the accuracy of paid and denied UI claims and determine the source of any inaccuracies to improve UI administrative

\footnotetext{
${ }^{10}$ At the time of this paper, there are no states that currently receive UI initial claims via the Internet exclusively.

${ }^{11}$ In a nationwide survey of 2,773 claimants, Marcus and Frees (1998) report that respondents estimated it took 11 minutes to file an initial claim by telephone and 61 minutes to file in person. A similar picture of considerable time savings from telephone claiming was also found in surveys of claimants in San Diego (2.33 hours in person to 14 minutes via phone) and Colorado ( 3.4 hours to 1.7 hours).

12 The time savings (in minutes) were 19 for Colorado, 9 for Utah, and 7 for Washington relative to filing a claim over the phone.

${ }^{13}$ As one anonymous reviewer noted, the precise magnitude of the improvement in filing convenience is important for interpretation, but is ultimately unknown because the time reductions documented in claimant surveys may over- or understate the true change in convenience. For instance, the surveys may not factor in the hassle of collecting all the information needed for eligibility determination, irrespective of claiming technology, overstating the convenience increase. Alternatively, if there is an added hassle of waiting in line and dealing with claims takers at the office relative to applying from the comfort of home, time reductions will understate the increased convenience. Despite these caveats, our approach will still provide a credible evaluation of the impact of phone and Internet claiming systems on program participation, which should be of policy interest in and of itself.
} 

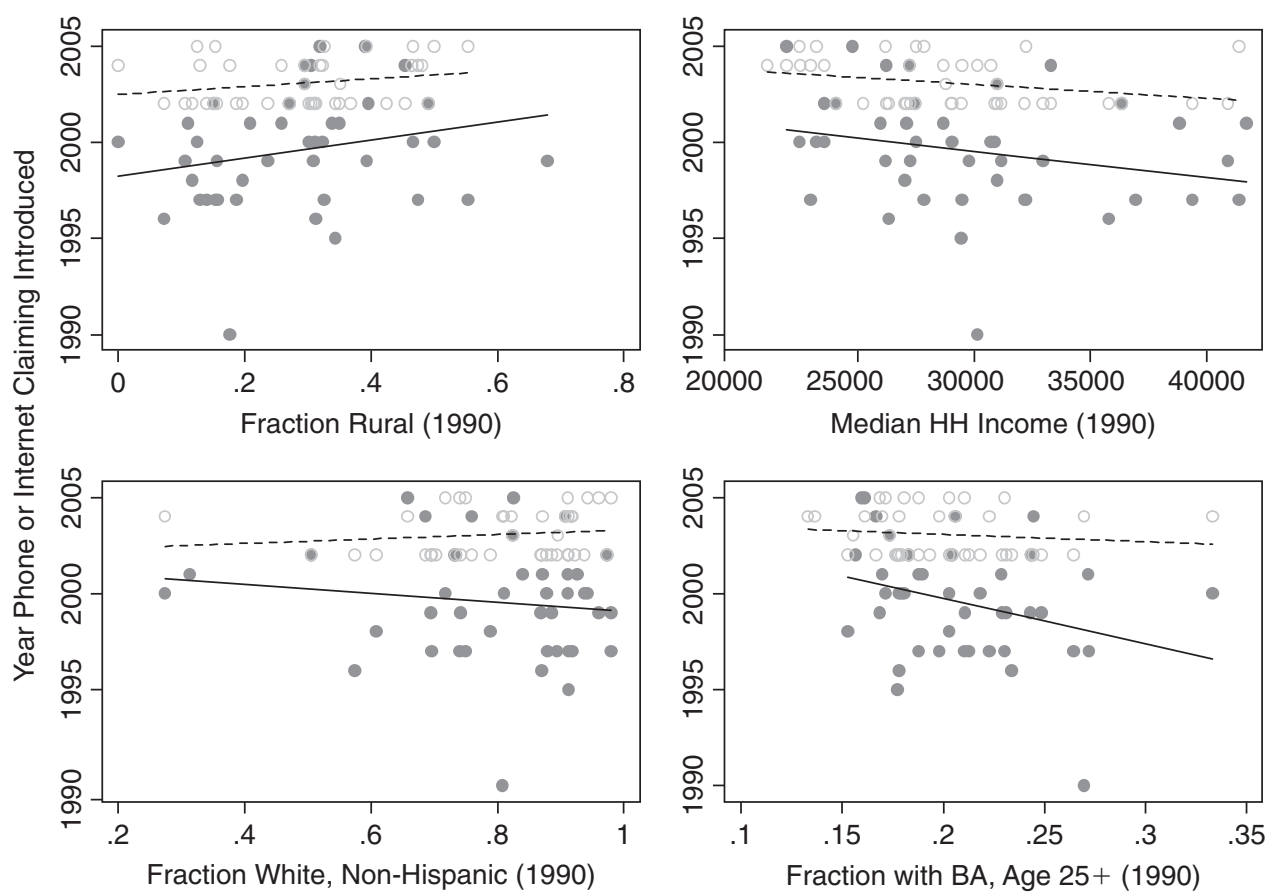

$\begin{aligned} \text { Phone } & =\text { Solid Line } \\ \text { Internet } & =\text { Dashed Line }\end{aligned}$

Sources: State demographic information is from the 1990 U.S. Census. Year of phone and Internet claiming introduction was constructed by the authors from various sources. See text for details.

Figure 5. Baseline Demographic Predictors of Policy Timing.

processes. BAM samples approximately 400 UI claimants per year in each state. ${ }^{14}$ Important for our purposes is that claiming method (in person, phone, mail, Internet, through employer) is recorded for each person in the sample. From this data, we estimate the fraction of UI claimants using each method in each state for every year and also measures of UI claimant characteristics (fraction at maximum benefit amount, pre-unemployment wages, and education).

Administrative data on the number of initial claimants, average duration on UI, number of weeks compensated and claimed, average weekly benefit amount, and several other measures of UI utilization were obtained from the Department of Labor Employment and Training Administration, quarterly by state. Program rules and regulations (such as the maximum benefit amount), the unemployment rate and the number of individuals unemployed, employed, and in the labor force were obtained from the same source. We construct two measures of UI program participation: weeks compensated per unemployed person and weeks compensated per UI-eligible unemployed person. Our method for estimating eligibility is described below. Finally, from the March CPS we obtain characteristics of the unemployed population in each year, which we use as control variables in our regression analysis. All nominal values for earnings, wages, and benefit amounts are converted to 2003 dollars using the CPI-U. Table 1 provides summary statistics of our data set.

${ }^{14}$ Since the sample is drawn from all claims in a given week, BAM overrepresents claimants with long durations. That is, they are weighted by weeks claimed. We also construct weights for the BAM sample using basic demographic information on the universe of all UI claimants also collected by the U.S. DOL to ensure that our BAM sample matches the race-gender composition of claimants in each state-year. 

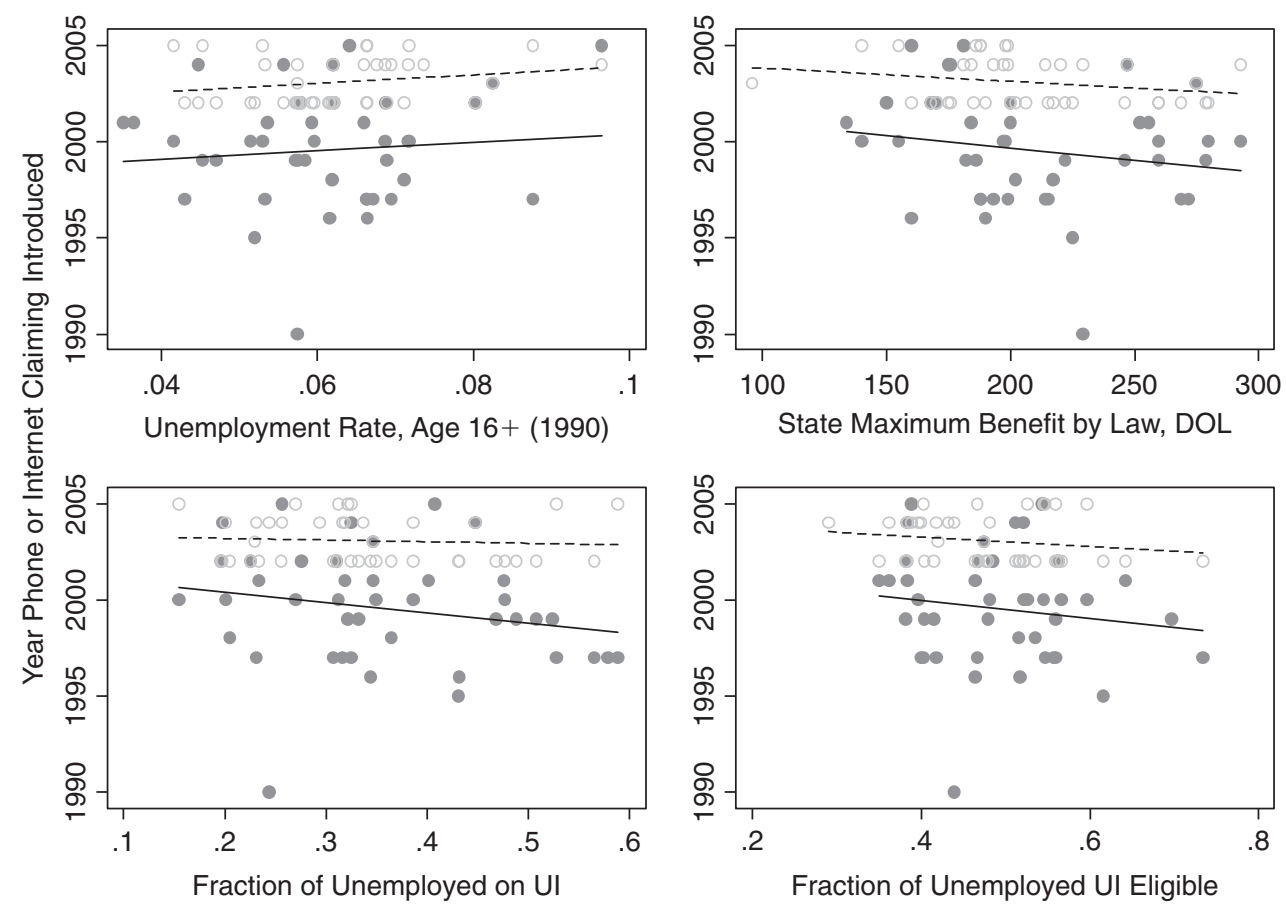

Phone $=$ Solid Line

Internet $=$ Dashed Line

Sources: Unemployment rate is from the 1990 U.S. Census. State maximum benefit amount is from the DOL ETA. Fraction of unemployed on UI was calculated by the authors from administrative sources. Fraction of unemployed workers eligible for UI was estimated by the authors from the March CPS. Year of phone and Internet claiming introduction was constructed by the authors from various sources. See text for details.

Figure 6. Baseline Labor Market Predictors of Policy Timing.

\section{Dating Policy Changes}

We identified the year in which states first offered phone claiming, first offered Internet claiming, and first closed UI offices (eliminating in-person claiming) using three complementary approaches. Identifying the conceptually appropriate date of implementation is complicated by the fact that some states piloted the initiatives in a few locations or gradually phased in implementation across the state, or both. Our primary analysis relies on policy dates inferred from sharp changes in trends in the methods used to file UI claims. For each state, we identified the year that the share of claims filed via phone (or Internet) accelerated by the greatest amount and designated it the event year. ${ }^{15}$ This approach allows us to account for both slow phase-in and the presence of special-case individuals filing by phone prior to its widespread implementation. ${ }^{16}$ Putting an exact date on office closure is also complicated by the gradual geographically based phase-in of many of the closures. We used the first year that in-person claims dropped below 20 percent as our office closure date.

\footnotetext{
${ }^{15}$ We calculated the absolute increase in the fraction of people using a filing method each year and determined the year in which this rate of growth increased the most. We restricted it to years where this maximum acceleration exceeded 5 percentage points and where the share was increasing, to prevent falsely recording minor blips as policy changes.

${ }^{16}$ Most states accepted some applications over the phone in the case of very special circumstances prior to the widespread implementation of phone claiming for all individuals.
} 
Table 1. Summary statistics.

\begin{tabular}{|c|c|c|c|c|}
\hline Variable & Mean & St. Dev. & Min. & Max. \\
\hline \multicolumn{5}{|l|}{ Measures of Participation } \\
\hline Fraction of unemployed on UI & 0.36 & 0.11 & 0.15 & 0.76 \\
\hline Fraction of unemployed eligible for UI & 0.47 & 0.10 & 0.19 & 0.79 \\
\hline Estimated UI take-up rate & 0.79 & 0.27 & 0.26 & 2.04 \\
\hline \multicolumn{5}{|l|}{ Characteristics of UI Recipients } \\
\hline Percent college degree & 0.11 & 0.05 & 0.03 & 0.49 \\
\hline Percent at max benefit amount & 0.24 & 0.16 & 0.00 & 0.9 \\
\hline Average pre-unemployment hourly wage & 13.83 & 2.19 & 9.17 & 21.82 \\
\hline \multicolumn{5}{|l|}{ UI Policies and Claiming Method } \\
\hline Max benefit amount $(\$ 100)$ & 3.14 & 0.67 & 1.35 & \\
\hline Post-phone & 0.34 & 0.47 & 0.00 & 1 \\
\hline Post-Internet & 0.17 & 0.38 & 0.00 & 1 \\
\hline Post close UI offices & 0.26 & 0.44 & 0.00 & 1 \\
\hline Percent claims filed in person & 0.65 & 0.40 & 0.00 & 1 \\
\hline Percent claims filed over phone & 0.23 & 0.35 & 0.00 & 1 \\
\hline Percent claims filed over Internet & 0.05 & 0.14 & 0.00 & 0.99 \\
\hline Percent claims filed postal mail & 0.03 & 0.10 & 0.00 & 0.8 \\
\hline Percent claims filed by employer & 0.02 & 0.05 & 0.00 & 0.37 \\
\hline Percent claims filed other method & 0.01 & 0.05 & 0.00 & 0.53 \\
\hline \multicolumn{5}{|l|}{ Characteristics of the Unemployed } \\
\hline Average age $(\times 10)$ & 3.10 & 0.36 & 1.90 & 4.50 \\
\hline Percent female & 0.42 & 0.08 & 0.18 & 0.72 \\
\hline Percent nonwhite & 0.25 & 0.19 & 0.00 & 0.91 \\
\hline Percent college degree & 0.10 & 0.06 & 0.00 & 0.40 \\
\hline Average weeks worked last year $(\times 10)$ & 2.55 & 0.37 & 1.31 & 3.76 \\
\hline Average weeks looking for work $(\times 10)$ & 1.54 & 0.45 & 0.52 & 3.13 \\
\hline Average earnings in previous year $(\$ 1000)$ & 10.98 & 4.10 & 3.33 & 35.53 \\
\hline
\end{tabular}

Notes: There are 918 state $\times$ year observations, corresponding to 51 states (including D.C.) and 18 years (1989 to 2006). Statistics are unweighted. All dollar variables are in 2003 dollars.

To verify our assignment of policy timing, we also contacted and interviewed 23 state UI offices directly, obtaining the dates of these three changes (if any) and some qualitative information about the process (that is, motivation and roll-out). We supplemented this information for six states using the dates reported in Needels et al. (2000) and from press releases. ${ }^{17}$ Our third approach involves identifying the year that phone or Internet claims exceed certain threshold of all claims. In this approach we designate the phone and Internet claiming year to be the first year that each method exceeded 5 percent of all claims. The office closing year was the first year that in-person claims dropped below 10 percent.

The dates for each of these events for each state using the first two methods (imputed and interviews) are reported in Appendix Table A1. ${ }^{18}$ Overall, the imputation seems to do a good job of capturing policy event dates: The correlations between imputed and interview-derived event dates (for adopting states) are 0.95, 0.64 , and 0.95 for phone claiming, Internet claiming, and office closure, respectively. We do not view the interview-derived dates as necessarily more preferable for quantifying the importance of time costs. If states implemented Internet claiming without advertising it or working out system kinks, then low initial utilization of

\footnotetext{
${ }^{17}$ We attempted to interview all states that were not profiled in Needels et al. (2000), but were able to speak with an administrator knowledgeable about the UI filing changes in only half of them.

${ }^{18}$ All appendices are available at the end of this article as it appears in JPAM online. Go to the publisher's Web site and use the search engine to locate the article at http://www3.interscience.wiley.com/cgi-bin/ jhome/34787.
} 
remote claiming implies negligible reduction in inconvenience. Our preferred analysis relies on policy events that had large and sudden impacts on the methods workers used to file a UI benefit claim.

\section{Estimating Eligibility}

In order to examine take-up among those eligible (rather than total participation), we follow Blank and Card (1991) and estimate the fraction of unemployed persons who are eligible for unemployment insurance in each state and year using data from the March CPS. ${ }^{19}$ Unemployed persons are deemed ineligible for five reasons: (1) current duration less than the required waiting period; (2) current duration exceeds the maximum; (3) quit last job; (4) not in a covered sector; and (5) insufficient base period earnings. We use earnings in the previous calendar year as our approximation of base period earnings.

Take-up is calculated as the ratio of the fraction of unemployed persons receiving UI (from the DOL) to the estimated fraction that are eligible. It should be noted that since eligibility is measured with considerable error, our take-up rates sometimes exceed 1 (in fact, the maximum in our data set is 2 ). This partly reflects systematic labor market differences between states. Alaska, for instance, has many migrant oil field workers and always has a very high estimated take-up rate because many people live outside the state (in the CPS) but claim UI benefits from Alaska (where they work). State fixed effects will net out these fixed differences across states. Appendix Table A $2^{20}$ presents the correlation between the fraction of unemployed who are on UI with our estimate of the fraction of unemployed who are UI eligible, by state and year. Overall, this correlation is 0.26 , which should be much closer to one if eligibility were accurately measured.

\section{Empirical Approach}

We utilize cross-state variation in the timing of changes to UI claiming procedures to assess the importance of convenience to UI program participation. States implemented phone- and Internet-based UI claiming at different times or sometimes not at all. This permits us to identify treatment effects separately from aggregate year effects and unobserved state characteristics, both of which may also influence takeup and claimant composition. We estimate the following simple reduced form model using weighted least squares with the number of unemployed persons in the state-year as weights:

$$
\begin{aligned}
\mathrm{y}_{i, t}= & \alpha_{0}+\alpha_{p} \text { PostPhone }_{i, t}+\alpha_{n} \text { PostNet }_{i, t}+\alpha_{c} \text { PostClose }_{i, t} \\
& + \text { State }_{i}+\text { Year }_{i}+\alpha_{b} \mathrm{~B}_{i, t}+\alpha_{x} X_{i, t}+\varepsilon_{i, t}
\end{aligned}
$$

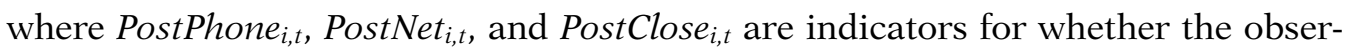
vation is after the policy change. Program characteristics such as the maximum weekly benefit amount are captured by $B_{i, t}$, and the characteristics of the unemployed population are captured by $X_{i, t}$. The error term $\varepsilon_{i, t}$ represents unmodeled determinants of take-up. The parameters of interest are $\alpha_{p}, \alpha_{n}$, and $\alpha_{c}$, which can be interpreted as the effect of having adopted remote UI claiming sometime in the past on UI take-up in the current period. We assume these effects to be constant across states and over calendar time. When a full set of state and year effects is included, these parameters are estimated on policy changes within states over time, net of any

\footnotetext{
${ }^{19}$ We are grateful to Brian McCall for generously sharing his code on UI eligibility regulations.

${ }^{20}$ All appendices are available at the end of this article as it appears in JPAM online. Go to the publisher's Web site and use the search engine to locate the article at http://www3.interscience.wiley.com/cgi-bin/ jhome/34787.
} 
aggregate yearly changes in UI take-up common to all states. Fixed differences in the levels of UI take-up across states will be absorbed into state fixed effects. Any aggregate correlation between policy changes and take-up, such as increased takeup during the 2001 recession, which coincided with the introduction of Internet claiming, will be absorbed into aggregate year effects. In equation (1), the unobserved counterfactual is implicitly estimated from individual state-level effects (identified by pre-event observations) and aggregate time trends (identified by control states with no policy changes).$^{21}$

There has been recent attention paid to the consistency of standard errors in regression frameworks similar to ours due to the possible within-state serial correlation of outcome and policy variables. Following Bertrand, Duflo, and Mullainathan (2004), we allow for an arbitrary variance-covariance structure by estimating a clustered robust covariance matrix (for example, clustered by state). We also utilize a nonparametric permutation test that assigns placebo patterns of treatment status to states and uses the empirical distribution of estimated coefficients from many of these placebo treatments for inference.

We can foresee at least three challenges to our identification strategy. First, states may have implemented other reforms that may also affect take-up (for example, expanded outreach) concurrent with changes to claiming methods. Depending on the nature of the reform, omitted variable bias may over- or understate the true causal effect. Our review of the literature and discussions with state UI administrators did not reveal any concurrent policy changes, but this cannot be entirely ruled out. ${ }^{22}$

A second problem is policy endogeneity. State administrators may adopt more automated claiming methods in response to higher anticipated demand placed on program resources due to higher anticipated take-up. If so, our estimates will be biased upwards. We address this concern by estimating "event study" models with leading and lagging treatment indicators, so we can observe pre-event trends in the outcome variables. To implement this, we estimate the following model using weighted least squares, again using number of unemployed persons as weights:

$$
\begin{aligned}
\mathrm{y}_{i, t}= & \alpha_{0}+\sum_{s=-3}^{3} \alpha_{p}^{s} \text { PhoneEvent }_{i, t}^{s}+\sum_{s=-3}^{3} \alpha_{n}^{s} \text { NetEvent }_{i, t}^{s}+\sum_{s=-3}^{3} \alpha_{n}^{s} \text { CloseEvent }_{i, t}^{s} \\
& + \text { State }_{i}+\text { Year }_{i}+\alpha_{b} \mathrm{~B}_{i, t}+\alpha_{x} X_{i, t}+\varepsilon_{i, t}
\end{aligned}
$$

where PhoneEvent $t_{i, t}^{s}$ is an indicator for time relative to the introduction of phone claiming. Phone Event $t_{i, t}^{s}$ equals 1 if state $i$ implemented phone claiming in period $t-s$ (where $s$ can be positive or negative), and 0 otherwise. NetEvent $t_{i, t}^{s}$ and CloseEvent $t_{i, t}^{s}$ are defined similarly. Coefficients on the policy event time indicators, $\alpha_{p}^{s}$ measure the differences between actual and predicted outcomes in the current period, having implemented the policy $s$ years earlier (if $s>0$ ). For instance, $\alpha_{p}^{0}$ is the take-up increase during the first year phone claiming was introduced relative to it not being implemented. These are the parameters of interest.

A third concern with our research design is power. If the time cost savings associated with filing method changes are low relative to expected UI benefits or other transaction costs such as repeated eligibility determination, then our analysis may provide only a low-power test of the time cost hypothesis. If application time is valued

\footnotetext{
${ }^{21}$ As one anonymous reviewer noted, the inclusion of unrestricted year fixed effects may reduce the power of our test since many states implemented remote filing in a short span of time. Post-treatment year effects are thus mostly identified by non-adopters. However, Figure 1 suggests that aggregate trends in participation are substantial, so we prefer models that control for unrestricted year fixed effects to those that do not.

${ }^{22}$ See Needels et al. (2000), Kenyon et al. (2003), and U.S. GAO (2005) for discussions of the implementation of remote claiming technologies.
} 
at the hourly wage rate and expected unemployment durations are long, then the time cost reductions may represent only a small equivalent benefit increase for the average worker. However, the time savings will be proportionately much more valuable for high-wage workers with low expected benefit durations. ${ }^{23}$

This concern underscores the importance of testing for heterogeneous effects. Also, we believe that initial application is much more burdensome than filing subsequent claims since the latter can be filed automatically over the phone, but this assumption has not been tested. Even with these limitations, our approach will still provide an unbiased estimate of the reduced-form effect of filing method on participation, which may be of policy interest of its own right.

\section{RESULTS}

\section{Effects on Claiming Method and Administrative Costs}

Though some states phased in phone claiming over time, on average adoption was rapid. Figures A1 to A3 in the Appendix ${ }^{24}$ plot the fraction of claims filed in person, by phone, and over the Internet separately for each state. To characterize the average pattern of adoption across all states, we first estimate equation (2) using the fraction with each filing method as dependent variables and plot the coefficients in Figure 7 . The regressions include a full set of state and year dummy variables but no other covariates. Conceptually, this procedure realigns the graphs in Figures A1 to A3 around a common vertical line at the time of each policy event to create a common "event time" relative to the event. The plotted coefficients $\alpha_{p}^{s}$ and $\alpha_{n}^{s}$ are the average deviation of each plot from the zero horizontal axis for each "event time" period. The top panel does not include indicators for office closure.

The estimates suggest that phone claiming grew to account for half of claims within two years of implementation, drawing almost exclusively from in-person claims (rather than employer-initiated, mail, or other methods). Internet claims also grew rapidly, mostly substituting for telephone and in-person claims. Including indicators for time relative to office closure (bottom panel) does not change the general pattern. Even when people retain the option of filing in person, the growth of phone and Internet claiming is still very rapid.

Cost reduction was one central motivation for states' move toward remote claiming. According to Needels et al. (2000), states believed that centralized call centers would allow them to realize economies in staff, office space, and training while making claiming easier for clients. They found that some states experienced a reduction in costs, while others did not. In some states, reductions in personnel and office space rental costs were offset by increases in communication and equipmentrelated costs. Kenyon et al. (2003) conclude that cost savings, improved efficiency, and convenience (extended hours and reduced wait time) also motivated the adoption of Internet claiming and that these improvements were achieved in the six states they studied.

To assess whether the policies had the intended effects on administrative costs, we collected data on employment and payroll from the Annual Survey of Government Employment and Payroll collected by the U.S. Census. Administration of the

\footnotetext{
${ }^{23}$ A two-hour application time reduction is equivalent to a 1 percent expected benefit increase, assuming 40 hours worked per week, a 40 percent replacement rate, and 14 weeks expected duration. However, the effect is much larger for those with lower expected durations (for example, 6 percent for a two-week duration). Given participation elasticities from Anderson and Meyer (1997) of 0.46 to 0.78, our state-level analysis may not be able to pick up the implied effects on participation if expected durations are high. We thank Patricia Anderson for suggesting this calculation.

${ }^{24}$ All appendices are available at the end of this article as it appears in JPAM online. Go to the publisher's Web site and use the search engine to locate the article at http://www3.interscience.wiley.com/cgi-bin/ jhome/34787.
} 


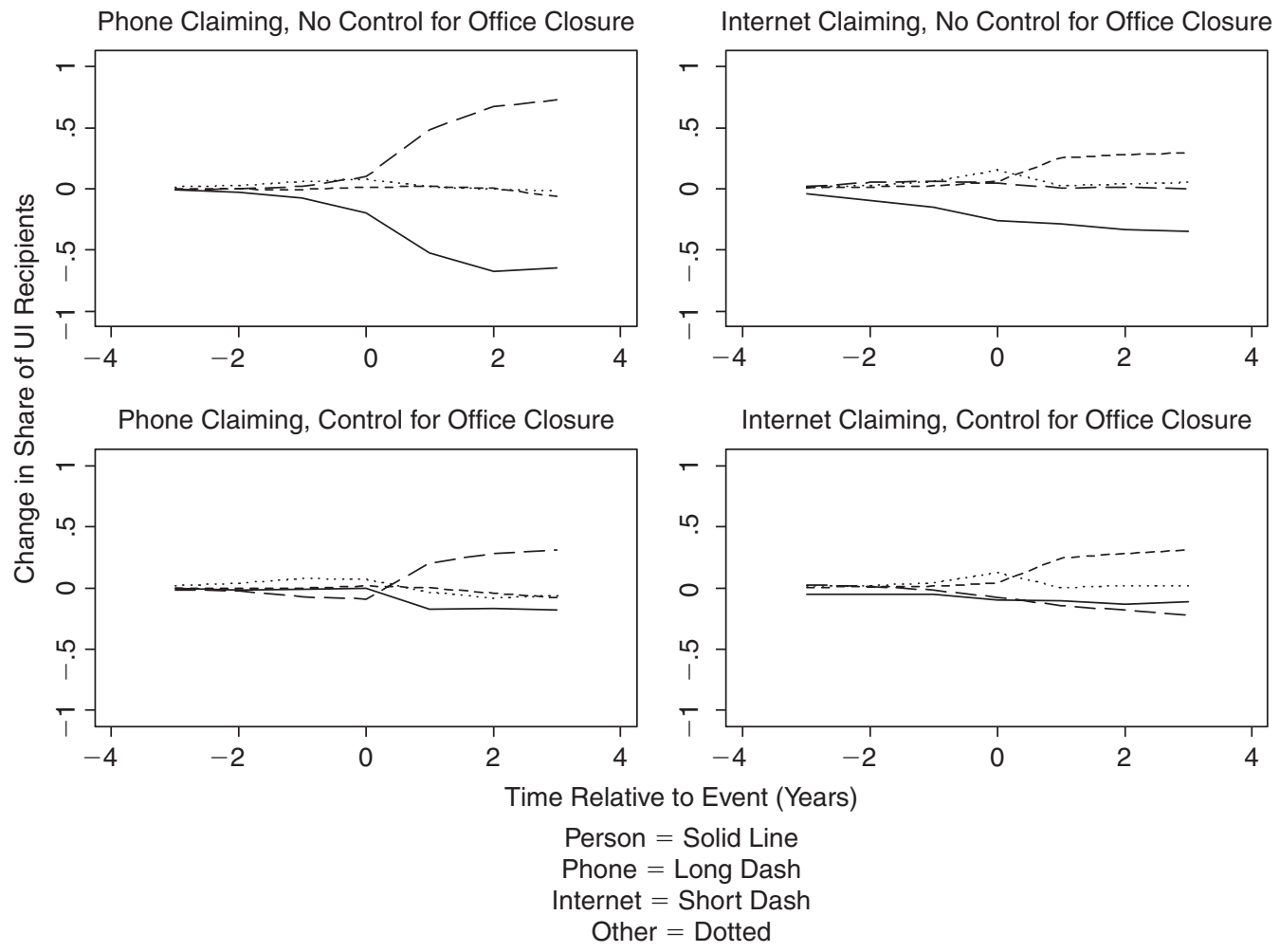

Notes: Graphs plot coefficients from WLS estimates of equation (2) without controls for covariates. See text.

Figure 7. Speed of Adoption after Policy Change.

federal-state unemployment compensation system is the primary component of expenditure function code 22, "Social Insurance Administration." 25 The data exclude benefits paid through the UI program and activities funded by federal job training programs. Table 2 presents estimates of equation (1) (excluding covariates) using employment and payroll costs as the dependent variables. The introduction of remote claiming in conjunction with office closure substantially reduced employment and payroll. Phone and Internet claiming on their own (without office closure) have no independent effect on employment costs. Also, these changes were not brought about by a shift toward more part-time employment. In fact, Internet claiming was associated with lower utilization of part-time staff. Figure 8 depicts the coefficients (and 95 percent confidence intervals) from event study estimates of log payroll, without indicators for office closure. Payroll fell approximately 2 years after the introduction of phone claiming, but the introduction of Internet claiming did not have an appreciable impact on administrative costs.

\section{Effects on Aggregate Take-up}

Table 3 presents our main results for aggregate take-up, using fraction of unemployed workers on UI as the dependent variable and weighting each state-year

\footnotetext{
${ }^{25}$ The total employment and payroll of the California Employment Development Department, whose primary task is administration of the UI program, accounts for about half of the employment and payroll reported for "Social Insurance Administration" in California (California Department of Finance, Salaries and Wages Supplement, various years).
} 
Table 2. Effect of remote claiming on UI administrative costs.

\begin{tabular}{|c|c|c|c|c|c|c|}
\hline & \multicolumn{2}{|c|}{$\begin{array}{l}\text { Log of FTE } \\
\text { Employment }\end{array}$} & \multicolumn{2}{|c|}{ Log of Payroll } & \multicolumn{2}{|c|}{$\begin{array}{c}\text { Fraction of } \\
\text { Employment PT }\end{array}$} \\
\hline & (1) & (2) & (3) & (4) & (5) & (6) \\
\hline Post-phone & $\begin{array}{c}-0.027 \\
(0.059)\end{array}$ & $\begin{array}{c}0.039 \\
(0.059)\end{array}$ & $\begin{array}{c}-0.030 \\
(0.064)\end{array}$ & $\begin{array}{c}0.036 \\
(0.058)\end{array}$ & $\begin{array}{c}0.011 \\
(0.012)\end{array}$ & $\begin{array}{c}0.013 \\
(0.009)\end{array}$ \\
\hline Post-Internet & $\begin{array}{c}0.032 \\
(0.057)\end{array}$ & $\begin{array}{c}0.068 \\
(0.047)\end{array}$ & $\begin{array}{c}0.022 \\
(0.054)\end{array}$ & $\begin{array}{c}0.058 \\
(0.045)\end{array}$ & $\begin{array}{c}-0.026^{*} \\
(0.015)\end{array}$ & $\begin{array}{r}-0.025^{*} \\
(0.015)\end{array}$ \\
\hline Post-close & & $\begin{array}{l}-0.129 * * \\
(0.054)\end{array}$ & & $\begin{array}{l}-0.131 * * * \\
(0.042)\end{array}$ & & $\begin{array}{r}-0.003 \\
(0.011)\end{array}$ \\
\hline Observations & 700 & 700 & 700 & 700 & 700 & 700 \\
\hline$R$-squared & 0.967 & 0.968 & 0.969 & 0.969 & 0.748 & 0.748 \\
\hline
\end{tabular}

Notes: All regressions include state and year fixed effects. Robust standard errors clustered by state in parentheses. There are 700 state $\times$ year observations, corresponding to 50 states and 14 years (1992 to 2006, excluding 1996). Outcome data are from the Annual Survey of Government Employment and Payroll collected by the U.S. Census, expenditure function code 22: "Social Insurance Administration."

* Significant at 90 percent; ** significant at 95 percent; *** significant at 99 percent.

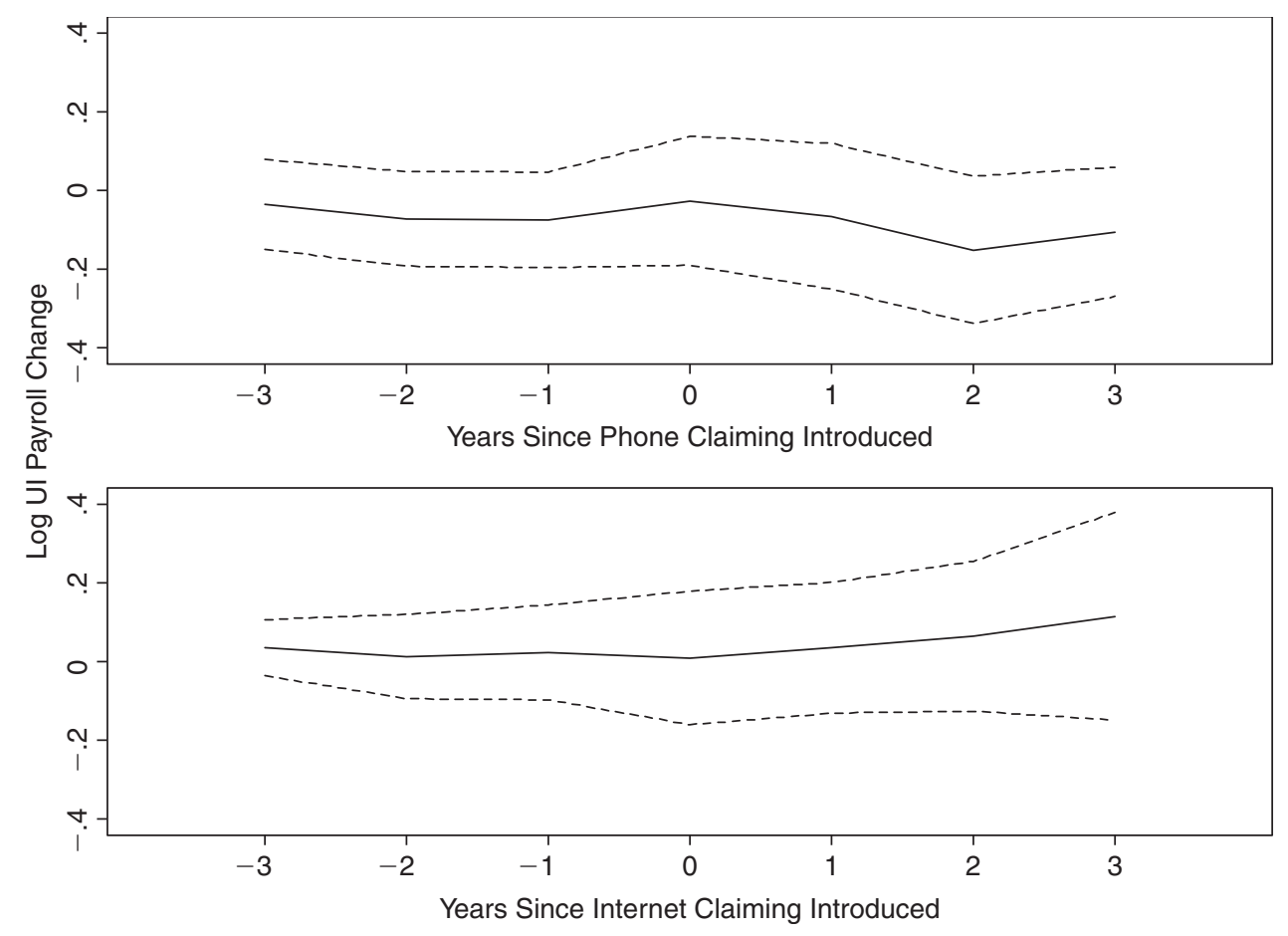

Notes: Graphs plot coefficients and 95 percent confidence intervals from WLS estimates of equation (2) without controls for covariates or indicators for office closure. See text. Payroll data are from the Annual Survey of Government Employment and Payroll from the U.S. Census and refer to expenditure function code 22, "Social Insurance Administration." Payroll is in \$2003.

Figure 8. Effect of Claiming Procedures on State Government UI Payroll Costs. 
Table 3. Effect of remote claiming on fraction of unemployed on UI.

\begin{tabular}{|c|c|c|c|c|}
\hline & \multicolumn{4}{|c|}{ Fraction of Unemployed on UI } \\
\hline & (1) & $(2)$ & (3) & (4) \\
\hline Post-phone & $\begin{array}{c}-0.002 \\
(0.010)\end{array}$ & $\begin{array}{c}0.003 \\
(0.010)\end{array}$ & $\begin{array}{c}0.004 \\
(0.010)\end{array}$ & $\begin{array}{c}0.004 \\
(0.010)\end{array}$ \\
\hline Post-Internet & $\begin{array}{r}-0.002 \\
(0.009)\end{array}$ & $\begin{array}{c}0.001 \\
(0.010)\end{array}$ & $\begin{array}{c}0.001 \\
(0.010)\end{array}$ & $\begin{array}{c}0.001 \\
(0.009)\end{array}$ \\
\hline Post-close & & $\begin{array}{c}-0.011 \\
(0.012)\end{array}$ & $\begin{array}{c}-0.011 \\
(0.012)\end{array}$ & $\begin{array}{c}-0.013 \\
(0.012)\end{array}$ \\
\hline Max. benefits $(\$ 100)$ & & & $\begin{array}{c}0.004 \\
(0.013)\end{array}$ & $\begin{array}{c}0.002 \\
(0.012)\end{array}$ \\
\hline Average earnings of unemployed ( $\$ 1000)$ & & & & $\begin{array}{l}0.002 \% * \\
(0.001)\end{array}$ \\
\hline Percent unemployed female & & & & $\begin{array}{c}-0.013 \\
(0.034)\end{array}$ \\
\hline Percent unemployed nonwhite & & & & $\begin{array}{r}-0.039 \\
(0.036)\end{array}$ \\
\hline Percent unemployed college & & & & $\begin{array}{r}-0.017 \\
(0.051)\end{array}$ \\
\hline Average age of unemployed $(\times 10)$ & & & & $\begin{array}{c}-0.001 \\
(0.007)\end{array}$ \\
\hline Average weeks worked last year $(\times 10)$ & & & & $\begin{array}{c}0.008 \\
(0.007)\end{array}$ \\
\hline Average weeks looking for work $(\times 10)$ & & & & $\begin{array}{c}-0.024 \\
(0.008)\end{array}$ \\
\hline Observations & 918 & 918 & 918 & 918 \\
\hline$R$-squared & 0.861 & 0.861 & 0.862 & 0.872 \\
\hline
\end{tabular}

Notes: All regressions include state and year fixed effects. Robust standard errors clustered by state in parentheses. There are 918 state $\times$ year observations, corresponding to 51 states (including D.C.) and 18 years (1989 to 2006). Fraction on UI is from administrative records.

* Significant at 90 percent; ** significant at 95 percent; *** significant at 99 percent.

observation by the number of unemployed persons in that particular state-year. UI participation does not increase with the introduction of either phone or Internet claiming once state and year effects are accounted for, as shown in column (1). The point estimates are negative and very close to zero, and their precision allows us to rule out positive effects of 1.7 and 1.5 percentage points at a 95 percent level of confidence for phone and Internet claiming, respectively. If some UI eligibles preferred making claims in person at UI offices, then phone claiming could actually be associated with reduced participation, since phones often replaced the in-person option. Column (2) includes an indicator for whether UI offices were closed. The coefficients on phone and Internet claiming increase slightly and are now positive, but still close to zero. Column (3) includes the real maximum benefit amount (in \$100) to account for any changes in the generosity of the UI system that happen to coincide with the adoption of remote claiming. The estimated coefficients are unaffected by this inclusion. Column (4) includes controls for various characteristics of the unemployed population from the CPS, including pre-unemployment average hourly wage, education, demographics, and recent labor market experience (weeks worked last year and weeks looking for work). These controls are generally insignificant, though the coefficient on weeks spent looking for work is negative, likely reflecting the exhaustion of (and ineligibility for) UI benefits during extended periods of unemployment. 
Table 4. Effect of remote claiming on take-up among UI eligible.

\begin{tabular}{|c|c|c|c|c|}
\hline & \multicolumn{4}{|c|}{$\begin{array}{c}\text { (Fraction of Unemployed on UI)/ } \\
\text { (Fraction of Unemployed Eligible for UI) }\end{array}$} \\
\hline & (1) & (2) & (3) & (4) \\
\hline Post-phone & $\begin{array}{r}-0.039 \\
(0.024)\end{array}$ & $\begin{array}{r}-0.009 \\
(0.033)\end{array}$ & $\begin{array}{r}-0.007 \\
(0.034)\end{array}$ & $\begin{array}{c}-0.008 \\
(0.031)\end{array}$ \\
\hline Post-Internet & $\begin{array}{c}-0.026 \\
(0.022)\end{array}$ & $\begin{array}{c}-0.006 \\
(0.026)\end{array}$ & $\begin{array}{c}-0.008 \\
(0.025)\end{array}$ & $\begin{array}{c}0.001 \\
(0.029)\end{array}$ \\
\hline Post-close & & $\begin{array}{r}-0.064 * \\
(0.034)\end{array}$ & $\begin{array}{r}-0.063^{*} \\
(0.034)\end{array}$ & $\begin{array}{c}-0.064 * \\
(0.036)\end{array}$ \\
\hline Max. benefits $(\$ 100)$ & & & $\begin{array}{c}0.017 \\
(0.021)\end{array}$ & $\begin{array}{c}0.024 \\
(0.023)\end{array}$ \\
\hline Average earnings of unemployed $(\$ 1000)$ & & & & $\begin{array}{c}0.001 \\
(0.004)\end{array}$ \\
\hline Percent unemployed female & & & & $\begin{array}{c}0.092 \\
(0.104)\end{array}$ \\
\hline Percent unemployed nonwhite & & & & $\begin{array}{c}-0.055 \\
(0.137)\end{array}$ \\
\hline Percent unemployed college & & & & $\begin{array}{l}-0.118 \\
(0.177)\end{array}$ \\
\hline Average age of unemployed $(\times 10)$ & & & & $\begin{array}{c}-0.037 \\
(0.024)\end{array}$ \\
\hline Average weeks worked last year $(\times 10)$ & & & & $\begin{array}{l}-0.132 * * * \\
(0.027)\end{array}$ \\
\hline Average weeks looking for work $(\times 10)$ & & & & $\begin{array}{c}0.0131 \\
(0.022)\end{array}$ \\
\hline Observations & 918 & 918 & 918 & 918 \\
\hline$R$-squared & 0.735 & 0.738 & 0.739 & 0.757 \\
\hline
\end{tabular}

Notes: All regressions include state and year fixed effects. Robust standard errors clustered by state in parentheses. There are 918 state $\times$ year observations, corresponding to 51 states (including D.C.) and 18 years (1989 to 2006). Fraction on UI is from administrative records. Fraction eligible are estimated from March CPS; see text for details.

* Significant at 90 percent; ** significant at 95 percent; *** significant at 99 percent.

The positive and significant coefficient on pre-unemployment earnings likely reflects UI eligibility. Our estimates in this preferred specification allow us to rule out positive effects of 0.023 and 0.019 percentage points for phone and Internet claiming, respectively. Since the average participation rate is 36 percent (Table 1), this implies that we can rule out an impact larger than a 6.4 (5.3) percent increase in participation in response to the provision of phone (Internet) claiming options (using the 95 percent confidence interval). The standard deviation of the participation rate for UI by state is 11 percentage points, implying that we can rule out an effect on participation larger than 21 (19) percent of a standard deviation.

\section{Accounting for Eligibility}

While the controls included in specification (4) of Table 3 may partially account for changes in eligibility, Table 4 offers another approach. In these specifications, we use the estimated take-up rate as a dependent variable. This is calculated as the ratio of the fraction of unemployed people on UI (from administrative sources) to the fraction of unemployed people eligible for UI (estimated from the March CPS). 
We believe that the denominator is estimated with considerable error, introducing quite a bit of noise into our outcome measure. ${ }^{26}$ This will decrease our precision considerably, but should not introduce any systematic bias into our estimates if this measurement error is uncorrelated with our explanatory variables.

Accounting for eligibility has little effect on our conclusions, though the point estimate is now negative for phone-based claiming and greater in magnitude. Since the mean of take-up is a little more than twice as large as the fraction of unemployed on UI, the coefficients should be divided by 2.2 to make them comparable to Table 3. As expected, standard errors are much larger due to eligibility measurement error. Together with the evidence in Table 3, we conclude that neither phonenor Internet-based claiming has an appreciable impact on participation in UI. It does appear, however, that office closure following the shift to phone claiming is associated with reduced take-up. We also find weak evidence that increasing the real maximum benefit amount results in higher participation, though our estimates are not statistically significant.

\section{Permutation Test for Inference}

To test the robustness of our inference for our main specification, we implement a nonparametric permutation test that assigns placebo patterns of treatment status to states and uses the empirical distribution of estimated effects from many of these placebo treatments for inference. This method is discussed by Johnston and DiNardo (1997, Chapter 11.2) and Bertrand, Duflo, and Mullainathan (2002) but has not found widespread use in the difference-in-difference literature. ${ }^{27}$ The benefit of this approach is that we do not have to specify anything about the structure of the error term, instead relying on the treatment randomization assumption (conditional on covariates).

To implement the test, we randomly assign each state one of the full treatment patterns of another state: $\left\{\right.$ PostPhone $_{i, t}$, PostNet $_{i, t}$, PostClose $\left._{i, t}\right\}$, drawing without replacement. Since six of the patterns are shared by two states each, there are $51 ! / 2^{6}$ possible permutations of states with treatments. We then estimate equation (1) using the placebo treatment patterns with OLSWLS, storing the coefficient estimates $\hat{\alpha}_{p, j}, \hat{\alpha}_{n, j}$, and $\hat{\alpha}_{c, j}$, where $j$ denotes the $j$ th randomization. This process is repeated a large number of times. We define $F($.$) to be the empirical distribution of$ these placebo treatment effect estimates. To test the hypothesis that our estimates using actual policy dates are statistically different from zero, we observe where they fall on the $F($.$) distribution. The 95$ percent confidence interval, for instance, is given by the $\hat{\alpha}_{n, j}$ that fall between the 0.025 and 0.975 percentiles of $F($.$) .$

Figure 9 plots the empirical distribution of $\hat{\alpha}_{p, j}$ and $\hat{\alpha}_{n, j}$ using 5,000 randomizations of treatment assignment. The solid vertical line is the point estimate from the base preferred model [Table 3, column (4)]. For both phone and Internet claiming, the point estimate is well within the distribution of point estimates from the placebo assignments. The 95 percent confidence interval is denoted by the dashed vertical lines. The width of this confidence interval is very similar to that derived using our state-clustered standard errors.

\section{Event Study Estimates}

In order to identify any preexisting trends in take-up that may bias our differencein-difference estimates, we estimated equation (2) both with and without indicators

\footnotetext{
${ }^{26}$ Table A2 in the Appendix presents the correlation between fraction of unemployed on UI and the estimated fraction eligible for UI by year and by state. Go to the publisher's Web site and use the search engine to locate the article at http://www3.interscience.wiley.com/cgi-bin/jhome/34787. Overall, the correlation is 0.26 , which should be closer to 1 if eligibility were accurately measured.

27 This is a variant of Fisher's permutation or randomization test (Fisher, 1935). Also see Chetty, Looney, and Kroft (in press) for a recent application.
} 

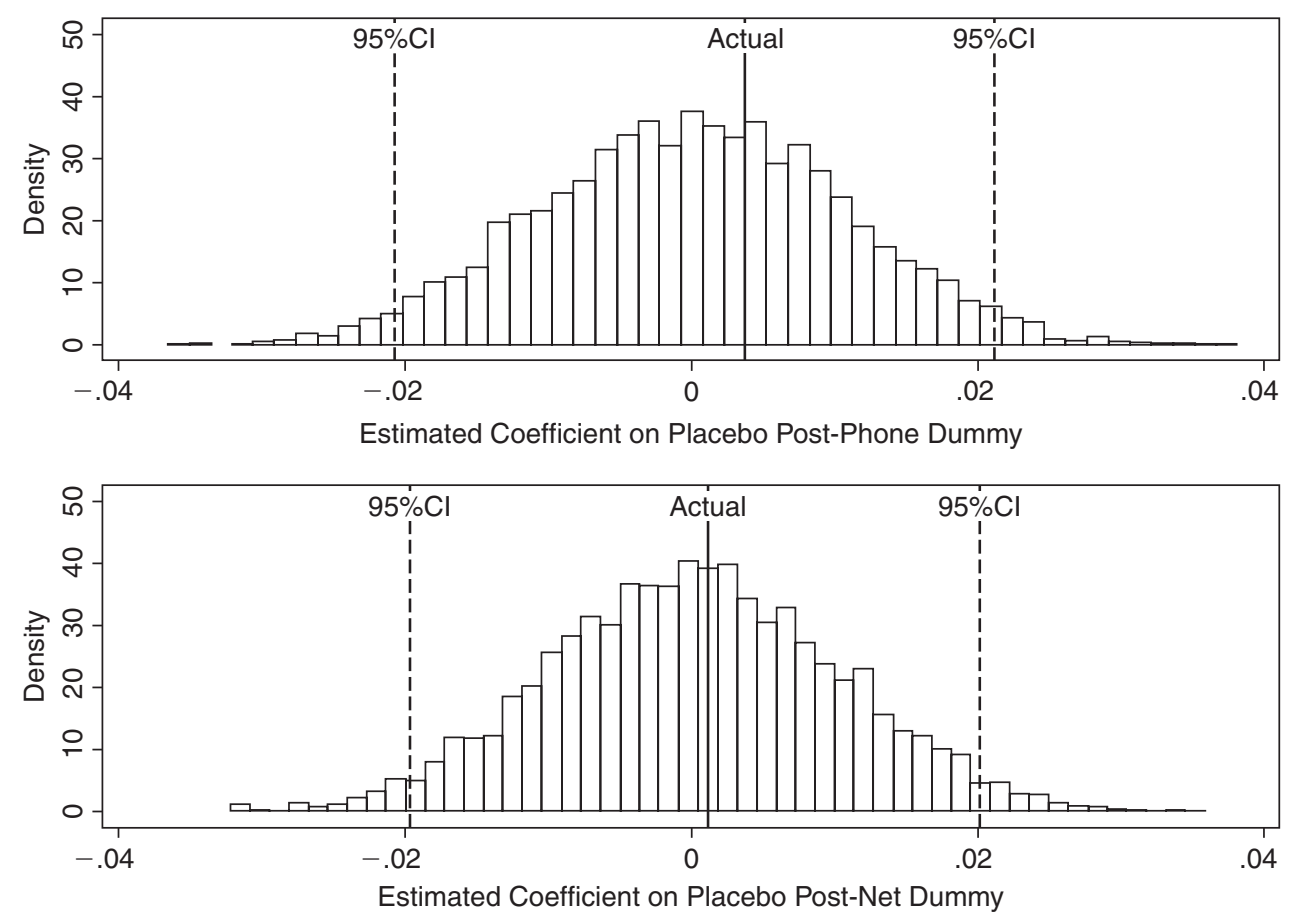

Notes: Figures plot the empirical distribution of estimated placebo treatment effects from 5,000 randomizations. Solid lines are the empirical 95 percent confidence intervals. Dashed lines are the actual treatment effect point estimates from Table 3, column (4). See text.

Figure 9. Permutation Test for Inference of Main Result.

for year relative to office closure. Figure 10 plots the coefficients from these regressions along with 95 percent confidence intervals. For phone claiming, there are no pre-event trends in participation regardless of whether office closure is controlled for, and the coefficients lie on the zero line. This suggests that phone claiming was implemented during a time that was "typical" for states. There appears to be a moderate short-term increase in participation following the introduction of phone claiming, but the estimate of this increase is very imprecise and not different from zero. Internet claiming, however, may have been implemented during a period of atypically low UI participation, as suggested by the negative- and downwardtrending pre-event coefficients. Though the confidence intervals are wide, our results on Internet claiming should be interpreted with caution. There also appears to be a short-term increase in participation coinciding with Internet claiming, but again this increase is not significant at conventional levels.

\section{Other Robustness Checks}

Table 5 presents several different checks on the robustness of our main findings using the fraction of unemployed on UI as our dependent variable. Column (1) just repeats our preferred base model estimates from Table 3, column (4). In specification (2), we include state-specific linear time trends to account for trends at the state level that are not picked up by aggregate year effects and the time-varying covariates we've included. This increases the magnitude of the phone and Internet 
Phone Claiming, No Control for Office Closure

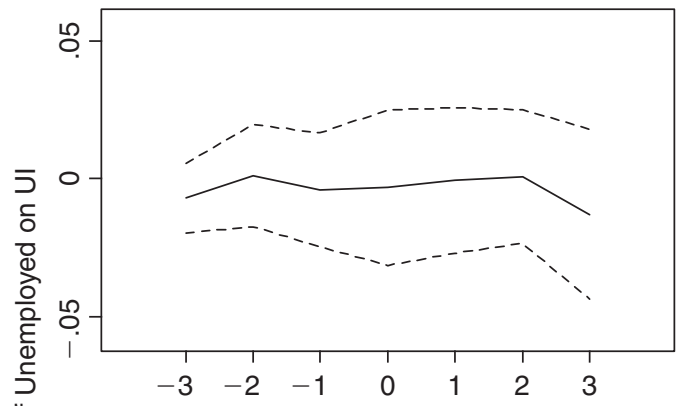

Phone Claiming, Control for Office Closure

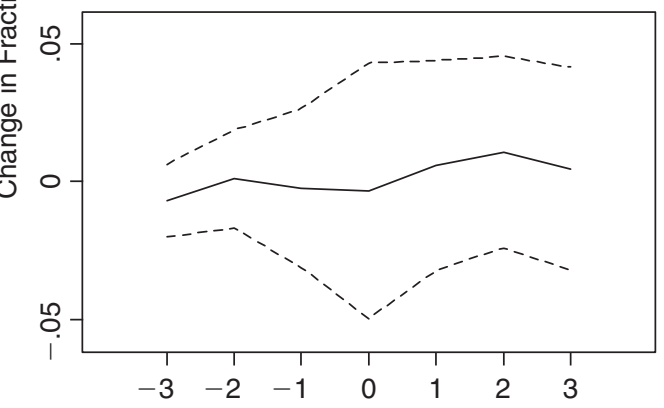

Internet Claiming, No Control for Office Closure

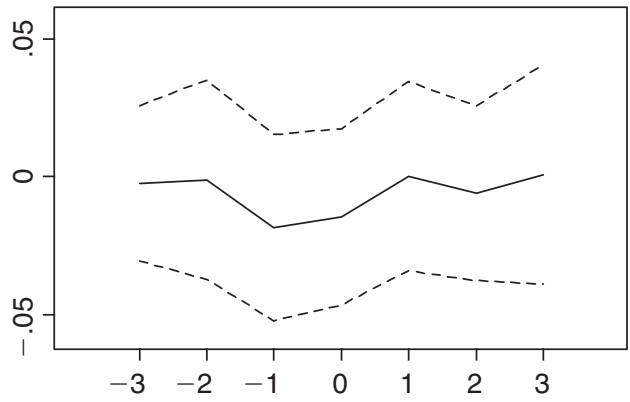

Internet Claiming, Control for Office Closure

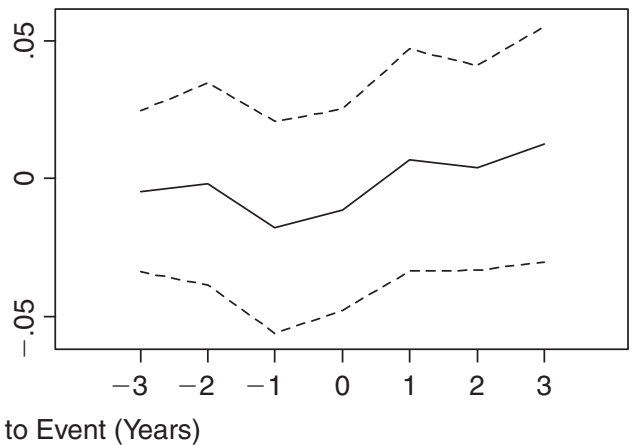

Notes: Graphs plot coefficients and 95 percent confidence intervals from WLS estimates of equation (2) with full controls for covariates, with and without indicators for office closure. See text.

Figure 10. Event Study Analysis of Fraction of Unemployed on UI.

claiming effects, but both are still insignificant and fall within the original confidence intervals. In (3) we instead include a linear time trend interacted with baseline demographic and labor market variables from the 1990 Census: median household income, fraction rural, fraction nonwhite, fraction with BA, unemployment rate, and not-in-labor-force rate. This inclusion changes our results very little from the base case.

Specifications (4) and (5) use alternative methods for identifying the years that states implemented phone and Internet claiming and closed UI offices. Specification (4) restricts analysis to only those states we were able to interview about the timing of their remote claims. Both coefficients become negative, but we still cannot reject that they are equal to zero. Identifying policy events as the first year that phone and Internet claims pass a 5 percent threshold (column 5) produces similar results as the base case.

The final specifications restrict the sample in different ways. One advantage of the staggered timing of policy adoption is that treatment effects can be estimated exclusively on the sample of states that adopted the policy, excluding control states that never adopt. Specifications (6) and (7) use only states that eventually implemented phone claiming and Internet claiming, respectively. In these specifications, later adopters serve as controls for earlier adopters. The estimated effects are larger when the sample is restricted to adopters, particularly for the policy (phone or Internet) whose enactment the sample is conditioned on, but they are still insignificant. Specification (8) restricts the sample to post-1994 observations for states that 


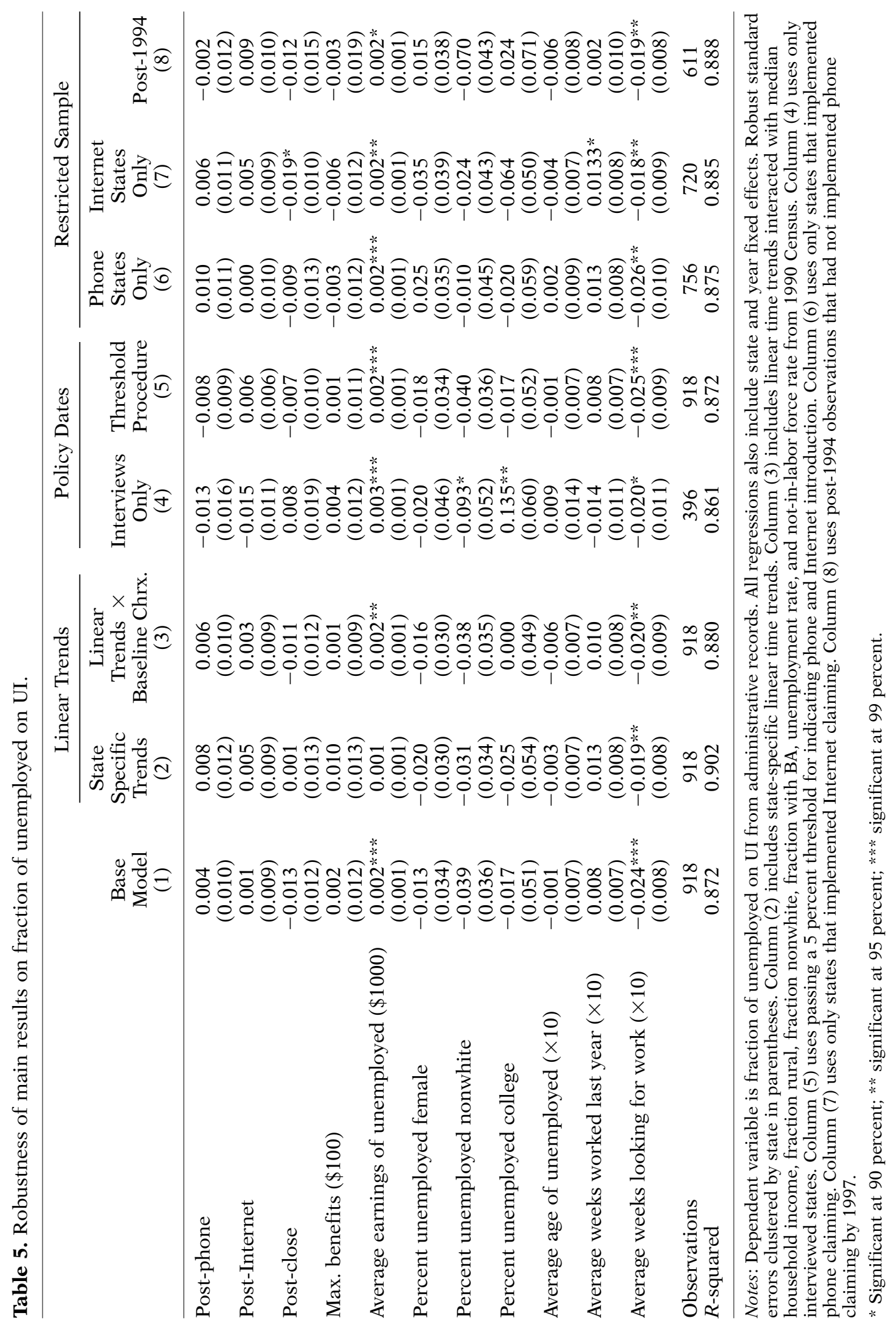


had not yet implemented phone claiming by 1997 . The intent is to estimate the state fixed effects using pre-treatment data that is closer to the date the policy changes actually happened. The estimates using this restricted sample are very similar to the base case.

\section{Effects on UI Recipient Characteristics}

If the policy changes affected potential UI recipients differentially-say because lower-income claimants preferred speaking directly to UI workers or had limited Internet access-then we may see changes in recipient characteristics even in the absence of aggregate take-up changes. Table 6 presents regression results where various characteristics of UI recipients are used as the dependent variables. We include a full set of controls for characteristics of unemployed people in each regression. Column (1) examines the fraction of UI recipients that are receiving the maximum benefit amount. Raising the maximum benefit level mechanically reduces this fraction. Internet claiming is positively related to the fraction at the maximum, and the coefficient on Internet claiming is different from zero at the 95 percent level of confidence.

Column (2) examines the fraction of UI recipients who have a college degree. If college graduates have greater facility with the Internet or easier eligibility determination over the phone, we may see a shift toward more college graduates following the adoption of these claiming methods. We find no evidence for such a shift. The point estimates are close to zero and statistically insignificant. However, we do see a slight increase in the fraction of college-educated following office closure.

In column (3), we use average real pre-unemployment hourly wage as the dependent variable. This provides a direct test of the time cost explanation for incomplete take-up if time spent applying for benefits is more costly to workers with higher wages. While the positive coefficients on Internet claiming are consistent with this explanation, the estimates are small ( $\$ 0.08$ on a base of $\$ 13.83$ ) and insignificant. If increased convenience primarily affects those whose time is most valuable, then we may expect to see greater effects higher on the wage distribution. Columns (4) to (7) address this issue by using different log wage percentiles of UI recipients as the dependent variable. The estimated effects of introducing phonebased claiming are consistently negative across the wage distribution. Internet claiming is, however, associated with higher earnings at the top end of the distribution.

Figure 11 provides graphical evidence on whether the wage distribution of UI recipients shifted in conjunction with the introduction of remote forms of UI claiming. We first estimate the density of log pre-unemployment real hourly wages for all UI recipients in all states in 1995, 2000, and 2005 using kernel density estimation on the BAM micro sample of UI recipients. The left panel plots the change in this density from 1995 to 2000 for all states and separately by whether states had or had not yet adopted phone claiming technology by 2000. This was the time period when more than half of all states did so, but Internet technology was not yet present. Though the wage distribution of all UI recipients shifted upward, there do not appear to be differential trends in the earnings distribution by phone claiming adoption. The right panel plots the change in log wage density from 2000 to 2005 for all states and separately by whether states had adopted Internet claiming technology by 2005. Again, we see no differential change in the earnings distribution of UI recipients by states' claiming technology.

In the context of finding only one significant change in the UI recipient population (fraction at maximum benefit amount) with the introduction of remote claiming, we conclude that increased filing ease had minimal impact on the characteristics of UI recipients. 


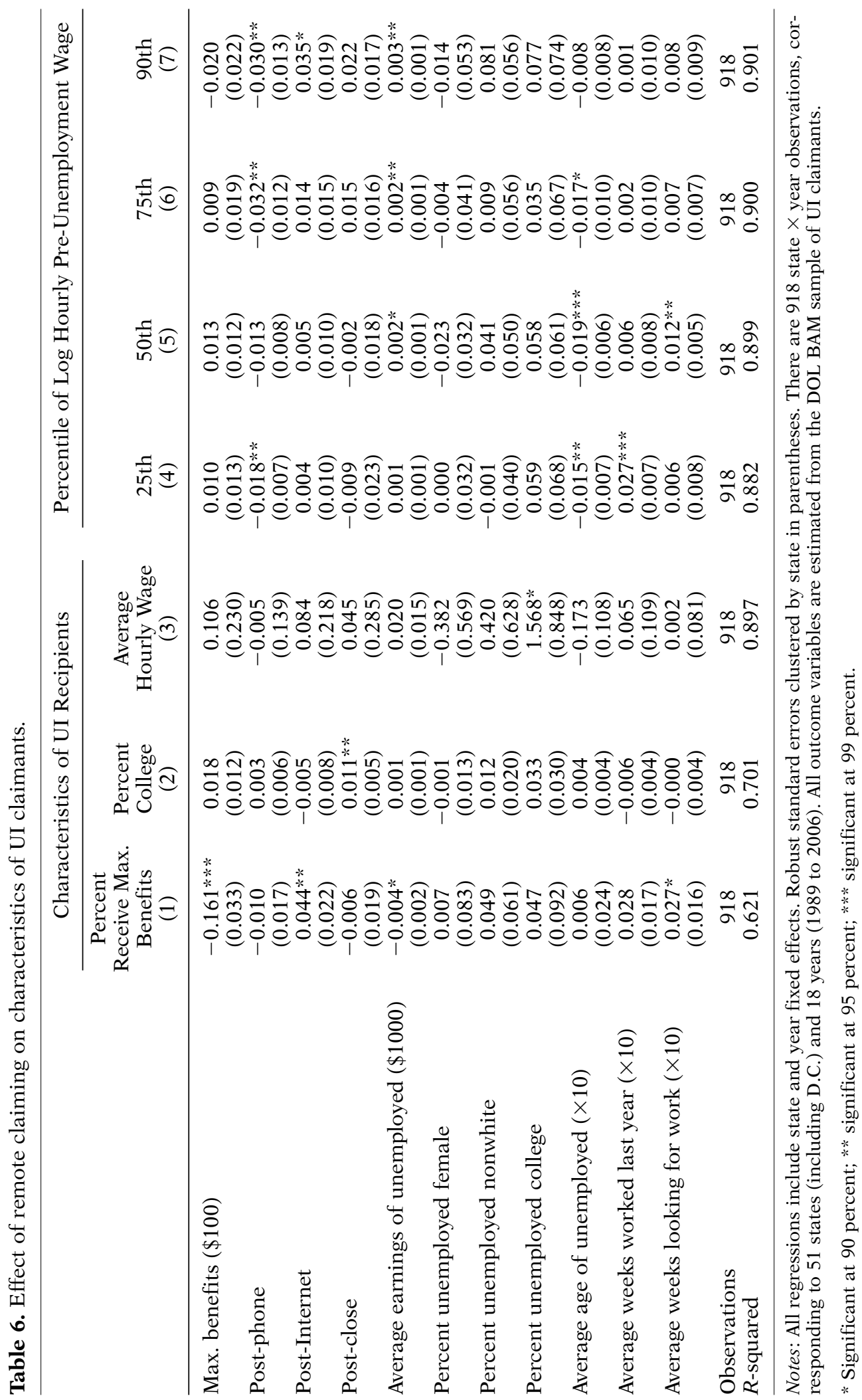


A. Change 1995-2000

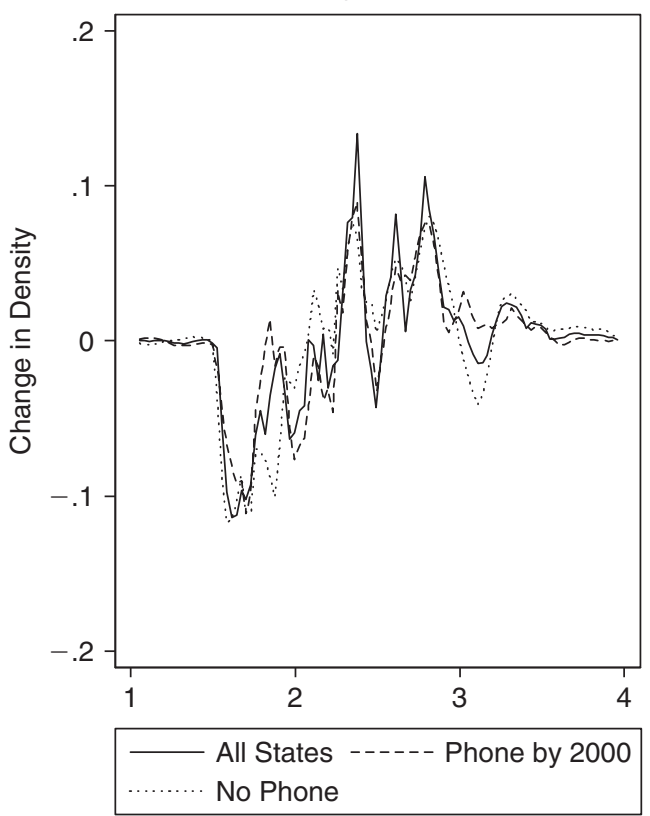

B. Change 2000-2005

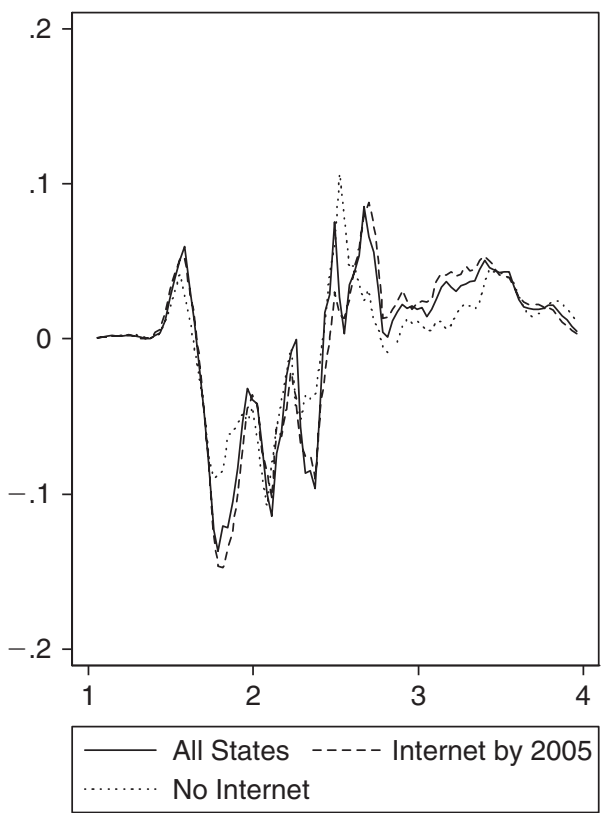

Pre-Unemployment Log Hourly Wage of UI Recipients (2003 Dollars)

Notes: Graphs plot changes in wage density estimated from the BAM sample of UI claimants. Kernel density estimates use the Epanechnikov kernel with optimal bandwidth and were calculated at 100 points. Weights used in the estimation were calculated using demographic characteristics of all UI claimants. Nominal wages are deflated by the CPI-U. Observations with real hourly wages greater than $\$ 50 /$ hour or less than $\$ 3 /$ hour were set to missing and not used in the estimates.

Figure 11. Change in Pre-Unemployment Wage Density by Policy Adoption.

\section{DISCUSSION AND CONCLUSION}

Our analysis suggests that states' adoption of remote forms of UI claiming (phone and Internet) did not have an appreciable impact on UI participation and take-up. At face value, this finding is inconsistent with a time- and transaction-cost explanation for low take-up if remote UI claiming is indeed less time-intensive, as claimant surveys suggest. However, interpreting our results as a strict rejection of the time-cost explanation requires that remote claiming reduced transaction costs considerably relative to expected UI benefits, which may not have been the case. We can conclude, however, that there are no additional effects of convenience beyond those obtained from the (small) implicit benefit increase and that the reduced-form effect of filing technology on participation is low. This latter finding may be of direct policy relevance as states have increasingly turned to phone- and Internetbased application procedures for many public benefit programs. For instance, a recent review found that nearly half of states now accept food stamps applications at least partially online (Center on Budget and Policy Priorities, 2009).

Our estimates are also sufficiently imprecise that we cannot rule out moderate effects of a few percentage point increase in take-up rates. Large to moderate effects for a small population of marginal claimants may not show up in state aggregate take-up rates. This possibility underscores the importance of testing for heterogeneous effects. The evidence on whether claimant characteristics changed with the advent of remote claiming is also weak. We conclude that the adoption of neither phone nor Internet claiming shifted the characteristics of UI claimants dramatically. 
One exception is that Internet claiming appears to be associated with greater participation by individuals at the top of the wage distribution, who are also more likely to receive the maximum benefit amount. States appear to have made considerable changes in administrative procedures and achieved substantial payroll cost reductions without a measurable impact on UI participation. One implication is that reducing application barriers alone may not be an effective tool for increasing program participation.

This finding differs from that of Kopczuk and Pop-Eleches (2007), who find that the introduction of electronic tax filing (e-filing) had a large effect on EITC participation. We speculate that differences in the role of intermediaries (e-filing occurs primarily through private tax preparers) and information (e-filing also provides information about EITC eligibility) may be important contextual differences between their study and ours. Movement to a system of employer-initiated automatic enrollment in unemployment insurance following job loss may be closer to the changes they examine than the ones we do and may be expected to have much larger effects. Future research about the role of program features, information, and intermediaries in participation is needed. Recent randomized field experiments funded by H\&R Block to test for presentation and inconvenience effects on participation in food stamps, federal financial student aid, and several other social programs holds particular promise.

AVRAHAM EBENSTEIN is a Lecturer in the Department of Economics at the Hebrew University of Jerusalem.

KEVIN STANGE is a Robert Wood Johnson Scholar in Health Policy Research at the University of Michigan.

\section{ACKNOWLEDGMENTS}

We are particularly thankful to Andy Spizak from the U.S. Department of Labor Employment Training Administration for providing us with the BAM data and to Brian McCall for sharing his UI eligibility programs. Helpful comments on earlier versions were received from Patricia Anderson, Alan Auerbach, Raymundo Campos, Raj Chetty, Marit Rehavi, Emmanuel Saez and seminar participants at U.C. Berkeley, the 2008 RWJ Health Policy Scholars Annual Meeting, and the 2009 AEA Annual Meetings. All errors are of course our own.

\section{REFERENCES}

Anderson, P., \& Meyer, B. (1997). Unemployment insurance take-up rates and the after-tax value of benefits. Quarterly Journal of Economics, 112, 913-937.

Ashenfelter, O., Ashmore, D., \& Deschenes, O. (2005). Do unemployment insurance recipients actively seek work? Evidence from randomized trials in four U.S. States. Journal of Econometrics, 125, 53-75.

Bansak, C., \& Raphael, S. (2006). The effects of state policy design features on take-up and crowd-out rates for the state children's health insurance program. Journal of Policy Analysis and Management, 26, 149-175.

Bertrand, M., Duflo, E., \& Mullainathan, S. (2002). How much should we trust differencesin-differences estimates? (NBER Working Paper No. 8841). Cambridge, MA: National Bureau of Economic Research.

Bertrand, M., Duflo, E., \& Mullainathan, S. (2004). How much should we trust differencesin-differences estimates? Quarterly Journal of Economics, 119, 249-275.

Blank, R., \& Card, D. (1991). Recent trends in insured and uninsured unemployment: Is there an explanation? Quarterly Journal of Economics, 106, 1157-1189. 
Budd, J., \& McCall, B. (1997). The effect of unions on the receipt of unemployment insurance benefits. Industrial and Labor Relations Review, 50, 478-492.

Budd, J., \& McCall, B. (2004). Unions and unemployment insurance benefits receipt: Evidence from the current population survey. Industrial Relations, 43, 339-355.

Center on Budget and Policy Priorities. (2009). Food stamps online: A review of state government food stamp websites. Washington, DC: Author.

Chetty, R., Looney, A., \& Kroft, K. (in press). Salience and taxation: Theory and evidence. American Economic Review.

Currie, J. (2006). The take-up of social benefits. In A. Auerbach, D. Card, \& J. Quigley (Eds.), Poverty, the distribution of income, and public policy (pp. 80-148). New York: Russell Sage.

Currie, J., \& Grogger, J. (2001). Medicaid expansions and welfare contractions: Offsetting effects on prenatal care and infant health? Journal of Health Economics, 21, 313-335.

Currie, J., \& Grogger, J. (2002). Explaining recent declines in food stamp program participation. Brookings-Wharton papers on urban affairs (pp. 203-229). Washington, DC: Brookings Press.

Daponte, B. O., Sanders, S., \& Taylor, L. (1999). Why do low-income families not use food stamps? Evidence from an experiment. Journal of Human Resources, 34, 612-628.

Fisher, R. A. (1935). The design of experiments. Edinburgh: Oliver and Boyd.

Hanratty, Maria J. (2005). Has the food stamp program become more accessible? Impacts of recent changes in reporting requirements and asset eligibility limits. Journal of Policy Analysis and Management, 25, 603-621.

Johnston, J., \& DiNardo, J. (1997). Econometric methods, 4th ed. New York: McGraw-Hill.

Kenyon, R., Needels, K., Anderson, T., Gerding, J., \& VanNoy, M. (2003). Internet initial claims evaluation. ETA Occasional Paper 2004-01. Washington, DC: U.S. Department of Labor.

Ketsche, P., Adams, E. K., Minyard, K., \& Kellenberg, R. (2007). The stigma of public programs: Does a separate S-CHIP program reduce it? Journal of Policy Analysis and Management, 26, 775-790.

Kopczuk, W., \& Pop-Eleches, C. (2007). Electronic filing, tax preparers and participation in the Earned Income Tax Credit. Journal of Public Economics, 91, 1351-1367.

Madrian, B. C., \& Shea, D. F. (2001). The power of suggestion: Inertia in 401(k) participation and savings behavior. Quarterly Journal of Economics, 116, 1149-1187.

Marcus, S. S., \& Frees, J. W. (1998). U.S. Department of Labor unemployment insurance claimant satisfaction study. Portland, OR: Bardsley and Neidhart, Inc.

McCall, B. P. (1995). The impact of Unemployment Insurance benefit levels on recipiency. Journal of Business \& Economic Statistics, 13, 189-198.

Needels, K., Corson, W., Meier, T., Harley, I., \& Blass, K. (2000). Evaluation of the impact of telephone initial claims filing. Princeton, NJ: Mathematica Policy Research, Inc.

O'Leary, C. J. (2006). State UI job search rules and reemployment services. Monthly Labor Review, 129, 27-37.

Remler, D. K., Rachlin, J. E., \& Glied, S. A. (2001). What can the take-up of other programs teach us about how to improve take-up of health insurance programs? NBER Working Paper No. 8185). Cambridge, MA: National Bureau of Economic Research.

Saez, E. (2009). Details matter: The impact of presentation and information on the take-up of financial incentives for retirement saving. American Economic Journal: Economic Policy, 1, 204-228.

U.S. Government Accountability Office. (2005). Unemployment Insurance: Better data needed to assess reemployment services to claimants. GAO Publication No. 05-413. Washington, DC: Author.

Vroman, W. (2002). Low benefit recipiency in state unemployment insurance programs. ETA Occasional Paper 2002-2. Washington, DC: Urban Institute.

Wandner, S., \& Stettner, A. (2000). Why are many jobless workers not applying for benefits? Monthly Labor Review, 123, 21-33.

Wolfe, B., \& Scrivner, S. (2005). The devil may be in the details: How the characteristics of SCHIP programs affect take-up. Journal of Policy Analysis and Management, 24, 499-522. 


\section{APPENDIX}

Table A1. Dates of changes in claiming method.

\begin{tabular}{|c|c|c|c|c|c|c|}
\hline \multirow[b]{2}{*}{ State } & \multicolumn{2}{|c|}{ Phone Claims } & \multicolumn{2}{|c|}{ Internet Claims } & \multicolumn{2}{|c|}{ Office Closure } \\
\hline & Imputed & Interview & Imputed & Interview & Imputed & Interview \\
\hline $\mathrm{AK}$ & 1997 & - & 2005 & - & 1997 & - \\
\hline AL & 2002 & 2002 & never & never & 2003 & 2002 \\
\hline AR & never & - & 2004 & - & never & - \\
\hline $\mathrm{AZ}$ & 2000 & - & 2005 & - & 2004 & - \\
\hline CA & 1996 & - & 2002 & - & 1998 & - \\
\hline $\mathrm{CO}$ & 1990 & 1991 & 2004 & 2005 & 1992 & 1991 \\
\hline $\mathrm{CT}$ & 2001 & 2001 & never & 2005 & 2003 & 2001 \\
\hline DC & 2000 & never & 2004 & 2005 & 2005 & never \\
\hline $\mathrm{DE}$ & never & never & never & never & never & never \\
\hline FL & 2002 & - & 2002 & - & 2002 & - \\
\hline GA & never & never & 2002 & never & never & never \\
\hline HI & 2001 & - & never & - & 2003 & - \\
\hline IA & 1999 & - & 2005 & - & never & - \\
\hline ID & never & - & 2002 & - & 2003 & - \\
\hline IL & 1997 & - & 2005 & - & never & - \\
\hline IN & never & - & 2003 & - & never & - \\
\hline KS & 1999 & - & 2002 & - & 1999 & - \\
\hline KY & never & - & 2004 & - & 2005 & - \\
\hline LA & 2005 & - & 2004 & - & never & - \\
\hline MA & 1997 & 1996 & never & never & 1998 & never \\
\hline MD & 1997 & 1997 & 2002 & 2002 & 2000 & 1997 \\
\hline ME & 1997 & 1997 & 2005 & 2006 & 1998 & 1997 \\
\hline MI & 2003 & - & 2003 & - & 2003 & - \\
\hline MN & 2000 & - & 2002 & - & 1999 & - \\
\hline MO & 1996 & 1997 & 2002 & 2003 & 1998 & 1997 \\
\hline MS & never & - & never & - & never & - \\
\hline MT & 1997 & 1997 & 2004 & 2005 & 1998 & 1997 \\
\hline NC & never & 2005 & never & 2003 & never & never \\
\hline ND & 2000 & 2001 & 2005 & 2004 & 2002 & 2001 \\
\hline $\mathrm{NE}$ & 2001 & 2001 & never & 2004 & 2002 & never \\
\hline $\mathrm{NH}$ & 2002 & never & 2002 & 2002 & 2004 & never \\
\hline NJ & 1999 & - & 2002 & - & 2001 & - \\
\hline NM & 2002 & - & 2002 & - & 2004 & - \\
\hline NV & 1998 & - & 2002 & - & 2001 & - \\
\hline NY & 1999 & 1998 & 2002 & 2001 & 2001 & 2002 \\
\hline $\mathrm{OH}$ & 2001 & 2002 & 2004 & 2004 & 2002 & 2003 \\
\hline OK & 2000 & 2000 & 2004 & 2004 & 2005 & 2003 \\
\hline OR & 2004 & 2004 & 2004 & 2005 & 2005 & 2005 \\
\hline PA & 2000 & - & 2002 & - & 2002 & - \\
\hline RI & 1997 & 1998 & 2002 & 2002 & 1999 & 1999 \\
\hline SC & 2004 & never & 2002 & 2002 & 2004 & never \\
\hline SD & 2000 & - & 2005 & - & 2002 & - \\
\hline TN & 2005 & 2001 & never & 2003 & never & never \\
\hline TX & 1998 & - & 2002 & - & 2000 & - \\
\hline UT & 1997 & 1997 & 2004 & 2000 & 1999 & 1997 \\
\hline VA & 2004 & 2003 & 2002 & 2002 & 2006 & never \\
\hline VT & 1999 & - & never & - & 2000 & - \\
\hline WA & 1999 & 1999 & 2002 & 2000 & 2000 & 1999 \\
\hline WI & 1995 & 1995 & 2002 & 2003 & 1996 & 1995 \\
\hline WV & never & never & never & never & never & never \\
\hline WY & 2001 & 2002 & 2002 & 2004 & 2002 & 2002 \\
\hline
\end{tabular}

Notes: Policy dates were imputed using the share of claims by filing method. The year in which the share of claims filed via phone (Internet) accelerated by the greatest amount was designated the event year. Office closure date was imputed as the first year that in-person claims fell below 20 percent. Missing values indicate that an interview was not conducted with that state nor was policy information found in published sources or news releases. 
Table A2. Correlation between fraction eligible for UI and fraction on UI.

\begin{tabular}{|c|c|c|c|c|c|c|c|}
\hline \multicolumn{2}{|c|}{ Within year } & \multicolumn{6}{|c|}{ Within state } \\
\hline 1989 & 0.06 & $\mathrm{AL}$ & -0.04 & KY & 0.30 & ND & 0.27 \\
\hline 1990 & 0.19 & $\mathrm{AK}$ & -0.10 & LA & -0.18 & $\mathrm{OH}$ & 0.45 \\
\hline 1991 & 0.02 & AZ & 0.53 & ME & 0.08 & OK & 0.50 \\
\hline 1992 & 0.21 & AR & 0.23 & MD & 0.12 & OR & 0.02 \\
\hline 1993 & 0.19 & CA & 0.65 & MA & 0.48 & PA & 0.60 \\
\hline 1994 & 0.20 & $\mathrm{CO}$ & 0.16 & MI & 0.35 & RI & 0.20 \\
\hline 1995 & 0.15 & $\mathrm{CT}$ & 0.20 & $\mathrm{MN}$ & 0.36 & $\mathrm{SC}$ & 0.50 \\
\hline 1996 & 0.27 & $\mathrm{DE}$ & -0.28 & MS & -0.06 & SD & 0.19 \\
\hline 1997 & 0.29 & DC & 0.51 & MO & 0.17 & $\mathrm{TN}$ & 0.69 \\
\hline 1998 & 0.29 & FL & 0.34 & MT & 0.27 & $\mathrm{TX}$ & 0.19 \\
\hline 1999 & 0.14 & GA & 0.22 & $\mathrm{NE}$ & -0.12 & UT & 0.49 \\
\hline 2000 & 0.34 & HI & 0.30 & NV & 0.45 & VT & 0.00 \\
\hline 2001 & 0.18 & ID & 0.22 & NH & 0.54 & VA & -0.17 \\
\hline 2002 & 0.24 & IL & 0.74 & NJ & 0.41 & WA & -0.02 \\
\hline 2003 & 0.41 & IN & 0.10 & NM & 0.39 & WV & 0.29 \\
\hline 2004 & 0.35 & IA & 0.52 & NY & 0.47 & WI & -0.06 \\
\hline 2005 & 0.36 & KS & 0.00 & $\mathrm{NC}$ & -0.21 & WY & 0.09 \\
\hline
\end{tabular}

All states, all years: 0.26

Notes: Fraction of unemployed on UI is from DOL administrative records and fraction of unemployed eligible for UI is estimated by the authors using the March CPS. See text for details on eligibility imputation. These measures were constructed at the state-year level and aggregated to the U.S. using the number of unemployed workers as weights.
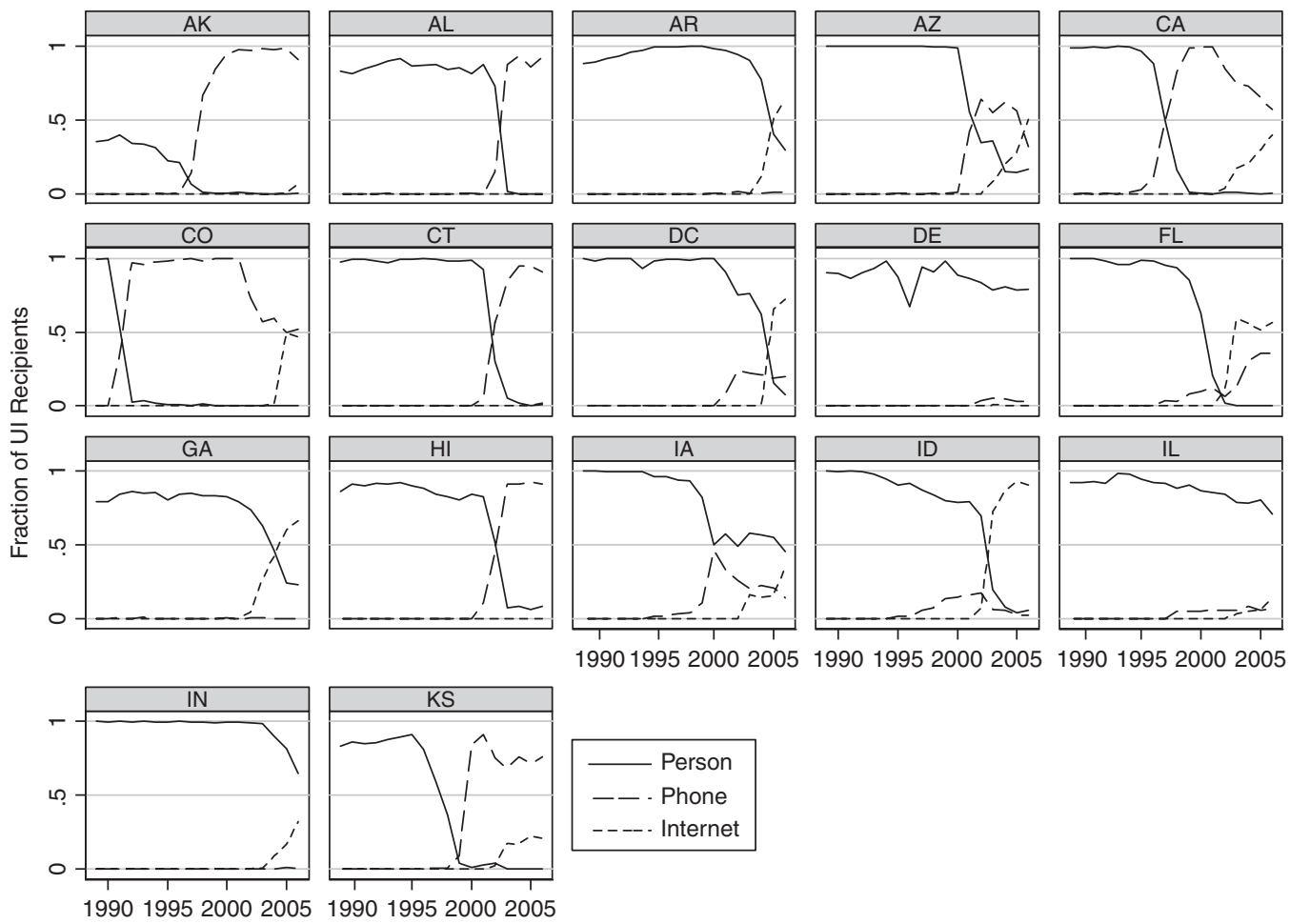

Figure A1. UI Claiming Method by State. 


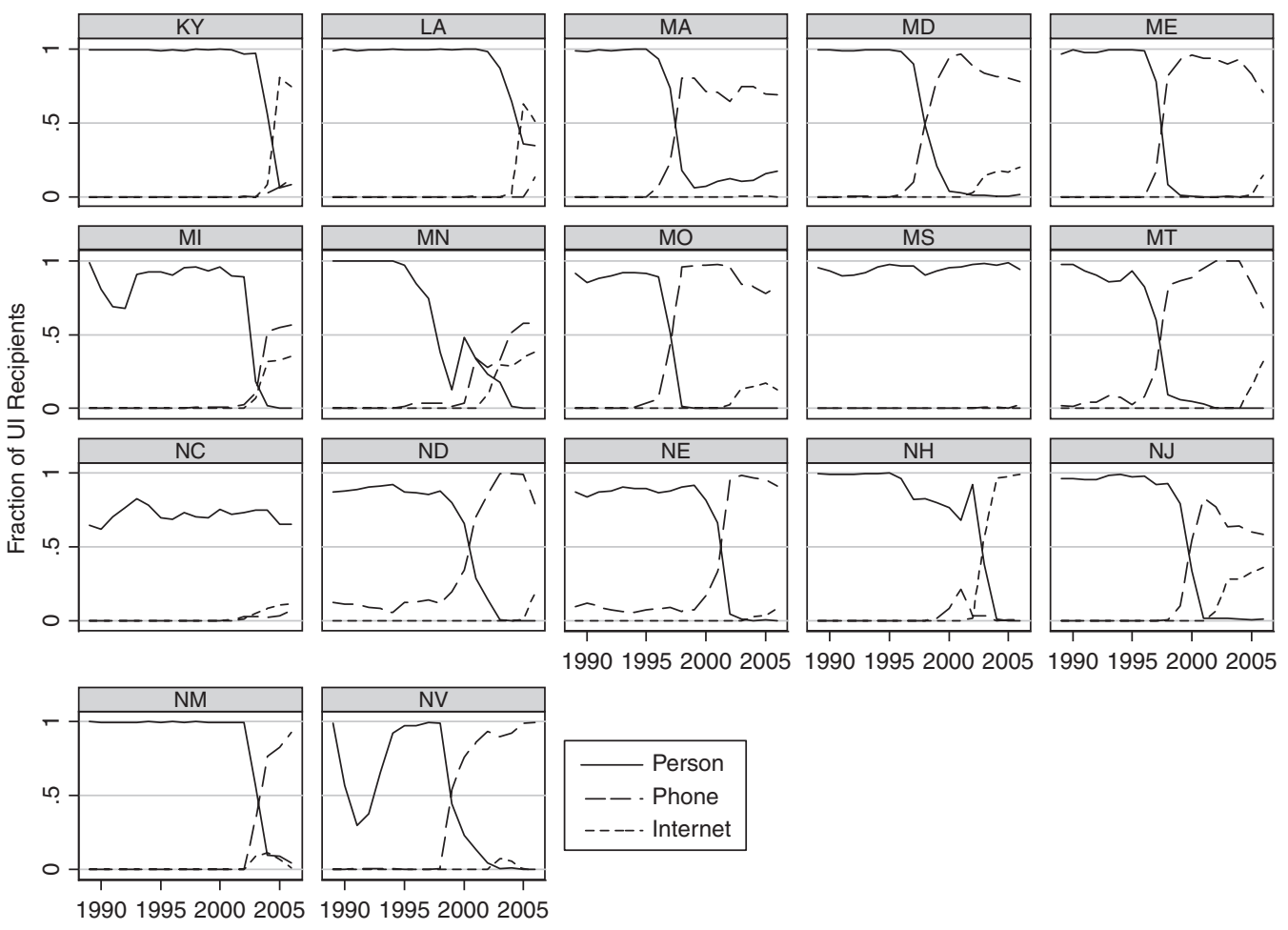

Figure A2. UI Claiming Method by State (continued).
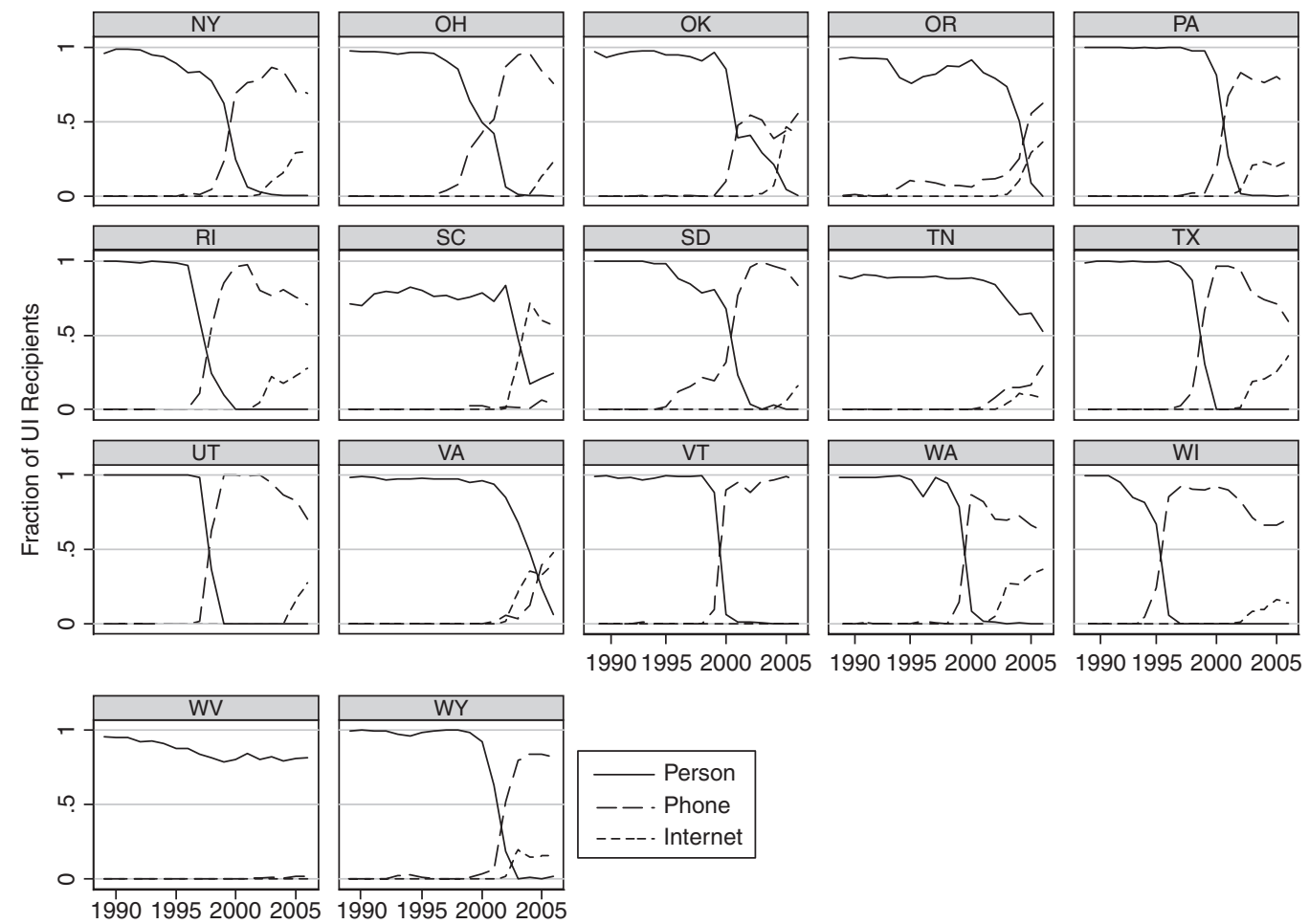

Figure A3. UI Claiming Method by State (continued). 